\title{
MULTIPLICIDADE DAS CIÊNCIAS VETERINARIAS NA ATUALIDADE
}

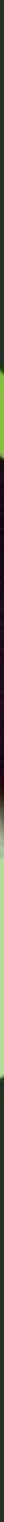

FELIPE JOSÉ DA COSTA ANDRADE MARDÔNIO LUAN VIEIRA DA SILVA ANNE VALÉRIA COSTA ALVES VITÓRIA DA SILVA PEREIRA

LEONARDO DA VINCI BOGÉA CONCEIÇÃO MARÍLIA GABRYELLE GUIMARÃES DE MACẾDO

ISABELLA LUSTOSA DOS SANTOS JOÃO HENRIQUE DE MORAES DOS SANTOS GISELLE BARBOSA RODRIGUES ROMÃO ALVES DO NASCIMENTO NETO 


\section{MULTIPLICIDADE DAS CIÊNCIAS VETERINARIAS NA ATUALIDADE}

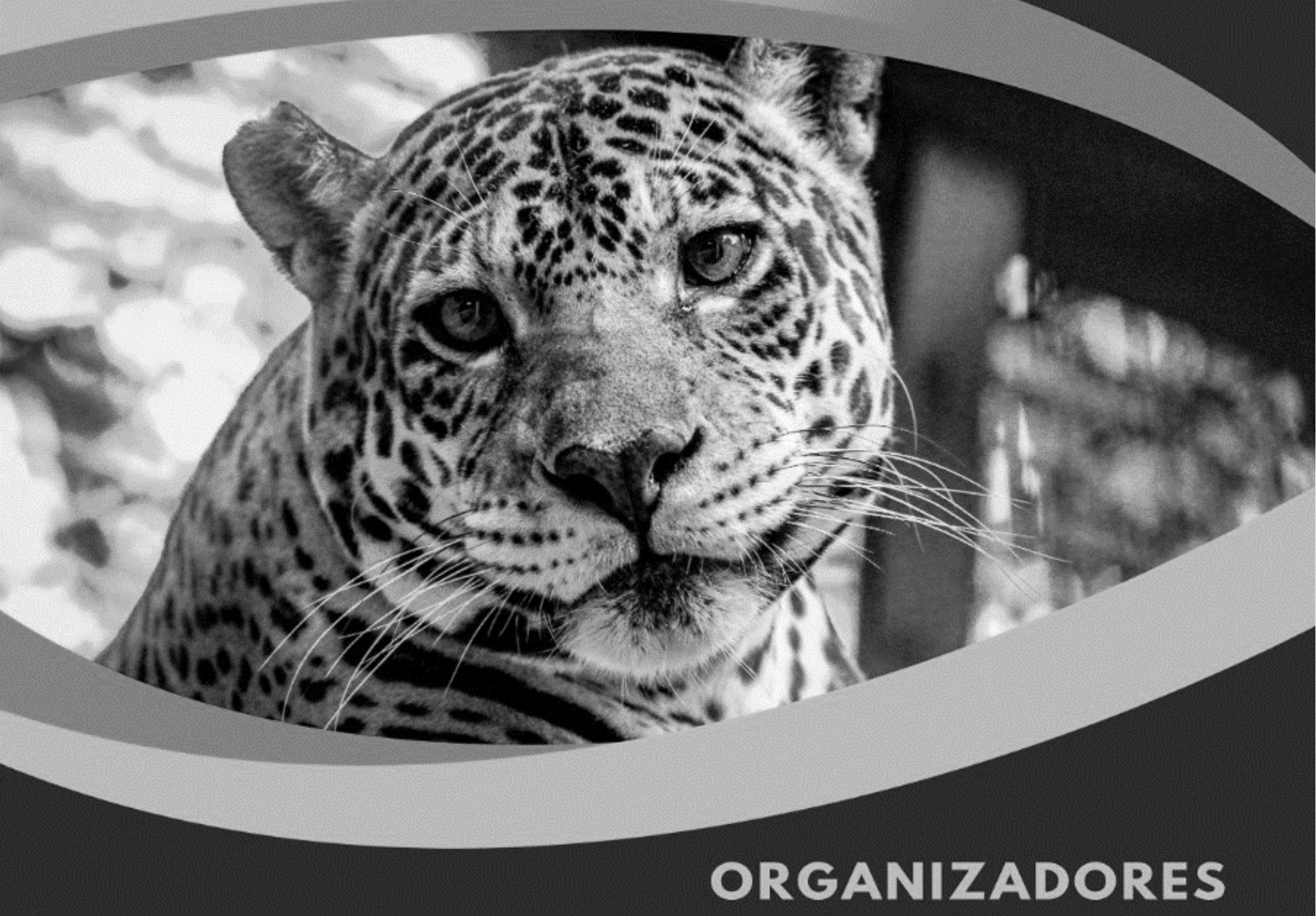

FELIPE JOSÉ DA COSTA ANDRADE MARDÔNIO LUAN VIEIRA DA SILVA ANNE VALÉRIA COSTA ALVES

VITÓRIA DA SILVA PEREIRA

LEONARDO DA VINCI BOGÉA CONCEIÇÃO MARÍLIA GABRYELLE GUIMARÃES DE MACẾDO

ISABELLA LUSTOSA DOS SANTOS JOÃO HENRIQUE DE MORAES DOS SANTOS GISELLE BARBOSA RODRIGUES ROMÃO ALVES DO NASCIMENTO NETO
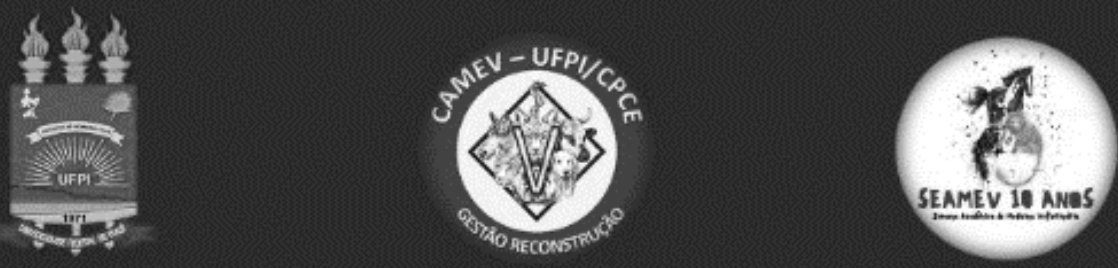
2021 by Editora In Vivo

Copyright (C) Editora In Vivo

Copyright do Texto (C) 2021 O autor

Copyright da Edição (C) 2021 Editora In Vivo

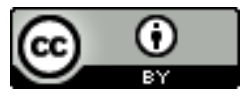

Esta obra está licenciada com uma Licença Creative Commons Atribuição 4.0 Internacional (CC BY 4.0).

O conteúdo desta obra e seus dados em sua forma, correção e confiabilidade são de responsabilidade exclusiva dos autores. Permitido o download da obra e o compartilhamento desde que sejam atribuídos créditos aos autores, mas sem a possibilidade de alterá-la de nenhuma forma ou utilizá-la para fins comerciais.

Editor Chefe

Dr. Everton Nogueira Silva

\section{Colégio de Ciências da Vida 1.1 Ciências Agrárias}

Dr. Aderson Martins Viana Neto

Dra. Ana Paula Bezerra de Araújo

MSc. Edson Rômulo de Sousa Santos

Dr. Fágner Cavalcante P. dos Santos

MSc. Filomena Nádia Rodrigues Bezerra

Dra. Lina Raquel Santos Araújo

Dr. Luis de França Camboim Neto

MSc. Maria Emília Bezerra de Araújo

MSc. Yuri Lopes Silva

\subsection{Ciências Biológicas}

Dra. Antonia Moemia Lúcia Rodrigues Portela

1.3 Ciências da Saúde

Dra. Ana Luiza M. Cazaux de Souza Velho

Dr. Isaac Neto Goes Silva

Dra. Maria Verônyca Coelho Melo

MSc. Paulo Abílio Varella Lisboa

Dra. Vanessa Porto Machado

Dr. Victor Hugo Vieira Rodrigues

\section{Conselho Editorial}

2 Colégio de Humanidades

\subsection{Ciências Humanas}

Dra. Alexsandra Maria Sousa Silva

MSc. Francisco Brandão Aguiar

MSc. Julyana Alves Sales

2.2 Ciências Sociais Aplicadas

MSc. Cícero Francisco de Lima

MSc. Erivelton de Souza Nunes

Dra. Maria de Jesus Gomes de Lima

MSc. Maria Rosa Dionísio Almeida

MSc. Marisa Guilherme da Frota

3 Colégio de Ciências Exatas, Tecnológica

e Multidisciplinar

3.1 Ciências Exatas e da Terra

MSc. Francisco Odécio Sales

Dra. Irvila Ricarte de Oliveira Maia

3.2 Engenharias

MSc. Amâncio da Cruz Filgueira Filho

MSc. Gilberto Alves da Silva Neto

MSc. Henrique Nogueira Silva

Dr. João Marcus Pereira Lima e Silva

MSc. Ricardo Leandro Santos Araújo

Dados Internacionais de Catalogação na Publicação - CIP

C176m Andrade, Felipe José da Costa.
Multiplicidade das ciências veterinárias na atualidade [livro eletrônico]. / Organizadores:
Andrade, Felipe José da Costa et al. Fortaleza: Editora In Vivo, 2021.
69 p.
Bibliografia.
ISBN: 978-65-993899-4-8
DOI: 10.47242/978-65-993899-4-8
1.Ciências Veterinárias. 2. Ciências Agrárias - Multiplicidade. I. Título.

CDD 630

Denise Marques Rodrigues - Bibliotecária - CRB-3/CE-001564/O 


\begin{abstract}
APRESENTAÇÃO
X Semana Acadêmica de Medicina Veterinária foi um evento online promovido através da cooperação entre a Universidade Federal do Piauí, Campus Professora Cinobelina Elvas - UFPI/CPCE e o Centro Acadêmico de Medicina Veterinária - CAMEV (UFPI/CPCE) nos dias 27 a 30 de outubro de 2020. Tendo como objetivo, a socialização de conhecimentos científicos, o incentivo à pesquisa e sua articulação com o ensino e a extensão, com vistas a enriquecer a formação oferecida ao corpo discente. Contou com palestras, submissão e apresentação de trabalhos.

Este livro apresenta um compilado de trabalhos realizados por discentes docentes, mestres, doutorandos e pesquisadores das áreas de animais silvestres, clínica médica e cirúrgica, comportamento e bem-estar animal, produção e melhoramento animal, saúde única e diversas outras áreas da medicina veterinária.

Esperamos que este livro seja uma obra proveitosa para os seus leitores que procuram atualizações e novas formas de aplicação de tecnologias na medicina veterinária atual.

Felipe José da Costa Andrade Mardônio Luan Vieira da Silva
\end{abstract}

\title{
Organizadores:
}

Felipe José da Costa Andrade ${ }^{1}$

Mardônio Luan Vieira da Silva ${ }^{1}$

Anne Valéria Costa Alves ${ }^{1}$

Vitória da Silva Pereira ${ }^{1}$

Leonardo Da Vinci Bogéa Conceição ${ }^{1}$

Marília Gabryelle Guimarães de Macêdo ${ }^{1}$

Isabella Lustosa Dos Santos ${ }^{1}$

João Henrique de Moraes dos Santos ${ }^{1}$

Giselle Barbosa Rodrigues ${ }^{1}$

Romão Alves do Nascimento Neto ${ }^{1}$

${ }^{1}$ Medicina Veterinária - Universidade Federal do Piauí, campus Professora Cinobelina Elvas - UFPI/CPCE. Bom Jesus-PI. 


\section{Fotografia de capa:}

Gabriel Vinicius Carvalho de Lucena

\section{Equipe Avaliadora:}

Lilian Silva Catenacci

Wagner Costa Lima

Kenney de Paiva Porfírio

Manoel Lopes da Silva Filho

Daniela Desgualdo Pires Osorio Bueno

David Germano Gonçalves Schwarz

Larissa Maria Feitosa Gonçalves

Márcia Paula Oliveira Farias 


\section{Sumário}

Capítulo 1 - DOI: 10.47242/978-65-993899-4-81

A RELAÇÃO ENTRE O AQUECIMENTO GLOBAL E O DECLÍNIO POPULACIONAL DE ANFÍBIOS - REVISÃO SISTEMÁTICA...............................9

Capítulo 2 - DOI: 10.47242/978-65-993899-4-82

ABORDAGEM CLÍNICA E CIRÚRGICA DO COLAPSO TRAQUEAL EM CÃES . .11

Capítulo 3 - DOI: 10.47242/978-65-993899-4-83

ACHADOS HISTOPATOLÓGICOS DE CINOMOSE EM GRAXAIM-DOCAMPO (LYCALOPEX GYMNOCERCUS FISCHER, 1814) .13

Capítulo 4 - DOI: 10.47242/978-65-993899-4-84

CONHECIMENTO ATUAL DA MICROBIOTA EM TARTARUGAS MARINHAS . .16

Capítulo 5 - DOI: 10.47242/978-65-993899-4-85

CORREÇÃO CIRÚRGICA DE URETER ECTÓPICO EM CÃES 18

Capítulo 6 - DOI: 10.47242/978-65-993899-4-86

DIAGNÓSTICO ULTRASSONOGRÁFICO DE CISTITE EM FÊMEA DE PORQUINHO DA ÍNDIA (CAVIA PORCELLUS) 20

Capítulo 7 - DOI: 10.47242/978-65-993899-4-87

DIETA DE ANTAS (TAPIRUS TERRESTRIS LINNAEUS, 1758) E A IMPORTÂNCIA PARA A DISPERSÃO DE SEMENTES EM TERRITÓRIO NACIONAL - REVISÃO SISTEMÁTICA 
Capítulo 8 - DOI: 10.47242/978-65-993899-4-88

DIVERSIDADE ALIMENTAR DA DIETA DE MYRMECOPHAGA TRIDACTYLA E TAMANDUA TETRADACTYLA DE VIDA LIVRE NO BRASIL - REVISÃO SISTEMÁTICA 24

Capítulo 9 - DOI: 10.47242/978-65-993899-4-89

DIVERSIDADE ENDOPARASITÁRIA EM VEADO-CAATINGUEIRO (MAZAMA GOUAZOUBIRA FISCHER, 1814) EM TERRITÓRIO NACIONAL REVISÃO SISTEMÁTICA 26

Capítulo 10 - DOI: 10.47242/978-65-993899-4-810

ENRIQUECIMENTO AMBIENTAL COM CHRYSOCYON BRACHYURUS EM CATIVEIRO 28

Capítulo 11 - DOI: 10.47242/978-65-993899-4-811

CAUSAS MORTIS EM PSITTACIFORMES NO BRASIL: UMA REVISÃO SISTEMÁTICA 30

Capítulo 12 - DOI: 10.47242/978-65-993899-4-812

PRINCIPAIS PLATELMINTOS QUE ACOMETEM ARRAIAS DO GÊNERO POTAMOTRYGON - REVISÃO SISTEMÁTICA ............................................. 33

Capítulo 13 - DOI: 10.47242/978-65-993899-4-813

REAÇÃO VACINAL EM FERRET: RELATO DE CASO 35

Capítulo 14 - DOI: 10.47242/978-65-993899-4-814

RELATO DE CASO DE FRATURA POR DOENÇA OSTEOMETABÓLICA EM FILHOTE DE JAGUATIRICA (LEOPARDUS PARDALIS LINNAEUS, 1758) .. 37

Capítulo 15 - DOI: 10.47242/978-65-993899-4-815

SINDROME DA BEXIGA NATATÓRIA - REVISÃO DE LITERATURA 39 
Capítulo 16 - DOI: 10.47242/978-65-993899-4-816

TÉCNICAS DE ENRIQUECIMENTO AMBIENTAL PARA LOBOS- GUARÁ (CHRYSOCYON BRACHYURUS ILLIGER, 1815) EX SITU - REVISÃO SISTEMÁTICA

Capítulo 17 - DOI: 10.47242/978-65-993899-4-817

UTILIZAÇÃO DA CRIOPRESERVAÇÃO ESPERMÁTICA APLICADA NA PRESERVAÇÃO DE GRANDES CARNÍVOROS - REVISÃO SISTEMÁTICA . 43

Capítulo 18 - DOI: 10.47242/978-65-993899-4-818

CIRURGIA DE FECALOMA EM FELINO: RELATO DE CASO 45

Capítulo 19 - DOI: 10.47242/978-65-993899-4-819

MANEJO TERAPÊUTICO PARA ASPERGILOSE EM PINGUIM-DEMAGALHÃES (SPHENISCUS MAGELLANICUS) 47

Capítulo 20 - DOI: 10.47242/978-65-993899-4-820

MONITORAMENTO DO VIBRIO CHOLERAE NA VIGILÂNCIA AMBIENTAL DE RECIFE-PERNAMBUCO

Capítulo 21 - DOI: 10.47242/978-65-993899-4-821

OS IMPACTOS DA URBANIZAÇÃO E CRENDICES POPULARES SOBRE OS OURIÇOS-CACHEIROS DA ESPÉCIE COENDOU SPINOSUS (F. CUVIER, 1823) 51

Capítulo 22 - DOI: 10.47242/978-65-993899-4-822

PRINCIPAIS ENDOPARASITOS QUE ACOMETEM O PEIXE-BOI-MARINHO (TRICHECHUS MANATUS MANATUS LINNAEUS, 1758) - REVISÃO SISTEMÁTICA 53 
Capítulo 23 - DOI: 10.47242/978-65-993899-4-823

PREVALÊNCIA DE LESÕES OCULARES EM PINÍPEDES (MAMMALIA: PINNIPIDAE) MANTIDOS EM CATIVEIRO - REVISÃO SISTEMÁTICA ..... 56

Capítulo 24 - DOI: 10.47242/978-65-993899-4-824

GASTROTOMIA EM CÃO DA RAÇA HUSKY SIBERIANO PARA RETIRADA DE MEIA - RELATO DE CASO. 58

Capítulo 25 - DOI: 10.47242/978-65-993899-4-825

LINFOMA DIFUSO DE CÉLULAS GRANDES - RELATO DE CASO 60

Capítulo 26 - DOI: 10.47242/978-65-993899-4-826

ICTIOFITIRÍASE - REVISÃO DE LITERATURA 62

Capítulo 27 - DOI: 10.47242/978-65-993899-4-827

ESPLENECTOMIA TOTAL EM CÃO COM NEOPLASIA MESENQUIMAL MALIGNA EM BAÇO - RELATO DE CASO 64

SOBRE OS ORGANIZADORES 66

ÍNDICE REMISSIVO 69 


\title{
A RELAÇÃO ENTRE O AQUECIMENTO GLOBAL E O DECLÍNIO POPULACIONAL DE ANFÍBIOS - REVISÃO SISTEMÁTICA
}

\author{
Gilmara Miguel SOUZA; Raphaela Bueno Mendes BITTENCOURT; Jhonatan Henrique \\ Lima DA ROCHA; Gabriel Vinícius Carvalho DE LUCENA; Felipe José da Costa
}

ANDRADE; Marina Neves de Assis AGUIAR; Aksa Ingrid Vieira BATISTA; Andrea

Moura DE CAMARGO.

E-mail de contato: gilmarasouzamiguel@gmail.com

Introdução: A classe Amphibia (Gray, 1825) é composta por vertebrados pecilotérmicos, com ausência de bolsa amniótica. Além disso, é realizada a diferenciação destes animais em 3 grupos, sendo eles: anuros, urodelos e os ápodes. Por apresentarem ectotermia, estes animais realizam as trocas de calor através da superfície cutânea e, mantêm taxas metabólicas menores do que indivíduos endotérmicos do mesmo tamanho, desta forma, a mudança de temperatura média ocasiona forte influência sobre os hábitos e bem-estar desses animais. Contudo, devido ao agravamento das mudanças climáticas nas últimas décadas, os índices de mortalidade entre as populações de anfíbios (principalmente anuros) os índices aumentaram exponencialmente, graças às elevadas temperaturas.

Metodologia: Este trabalho constitui uma revisão sistemática. A coleta de dados foi realizada durante o mês de setembro de 2020, para a pesquisa, foram utilizadas as bases de dados Google Acadêmico e SciELO. Foram baixados cerca de 15 artigos escritos ou editados entre os anos de 2000 e 2020 em inglês, português e espanhol. A partir do levantamento de dados, foram selecionados 3 livros, 2 revistas e 1 tese com temática acerca da biologia, comportamento e metabolismo de anfíbios, além de efeitos das mudanças climáticas.

Resultados: Os anfíbios são considerados o grupo de vertebrados mais ameaçado, uma vez que cerca de $40 \%$ das espécies constituintes, estão em perigo de extinção (HOFFMANN et al. 2010). De acordo com Wells (2007), a preferência destes vertebrados à regiões mais quentes explica sua maior ocorrência em regiões tropicais. Porém, mudanças no teor de umidade do ambiente (Pounds et al., 2006), diminuição do hidroperíodo (McMenamin et al. 2008) e outros fatores oriundos do aquecimento global, põe em risco a perpetuação das espécies em todo o planeta. De acordo com Pounds et al. (2006), nas últimas 3 décadas houve o declínio e desaparecimento de diversas populações de anfíbios, padrão nunca antes visto. Além disso, outra ameaça para os membros da classe Amphibia é o parasitismo tecidual por fungos da espécie Batrachochytrium dendrobatidis $(\mathrm{Bd})$, causadores uma infecção denominada quitridiomicose anfibiana. De acordo com a Cúpula de Conservação de Anfíbios (2005) esta é a mais devastadora doença infecciosa entre vertebrados, no que se refere ao número de espécies atingidas e à propensão de extinção das mesmas. Ademais, no mesmo estudo de 2006, Pounds e colaboradores confirmaram a existência de evidências que relacionam a epidemia de quitridiomicose anfibiana com a elevação das temperaturas médias na região. Por fim, trabalhos realizados por Deutsch et al. (2008) evidenciaram a menor margem de segurança térmica em vertebrados ectotérmicos e insetos, informações alarmantes sobre a sensibilidade destes indivíduos no que se refere à variação climática.

Conclusão: Conclui-se que, o aquecimento global é uma grande ameaça para as populações de anfíbios no mundo. É possível notar que diferentes mazelas oriundas das mudanças climáticas podem afetar estes animais, havendo o risco de extinção de muitas espécies. Logo, estudos como este incentivam a conservação dos animais que constituem a classe amphibia, através da exposição dos danos causados à essa população. 
Palavras-chave: Conservação, Anfíbios.

\section{Referências:}

SPITZEN, A.M.S.; ZOLLINGER R. Literature review on Batrachochytrium dendrobatidis. Fundação RAVON, Nijmegen, Holanda. 2010.

CUBAS, Z.S., SILVA, J.C.R., CATÃO DIAS, J.L. Tratado de Animais Selvagens. 2. Ed. São Paulo: Roca, 2014.

KENITIRO, S. Mudanças ambientais da Terra. São Paulo: Instituto Geológico, 336 p. 2008.

ARAÚJO, O.G.S., TOLEDO, L.F., GARCIA, P.C.A. \& HADDAD. Lista de anfíbios do Estado de São Paulo. Biota Neotropica. 2009.

NUNES, L.H. Repercussões globais, regionais e locais de aquecimento global. Terra Livre, ano 19, v. I, n. 20, p. 101-110, jan./jul. 2003.

POUGH, F., JANIS, C.M., HEISER, J.B. A vida dos vertebrados. 4. Ed. São Paulo: Atheneu, 684p. 2008.

SCHMIDT-NIELSEN, K. Fisiologia animal: adaptação e meio ambiente. $5^{a}$ ed., São Paulo: Santos, 611p. 2010.

VIEIRA, C.A. et al. First record of Batrachochytrium dendrobatidis in Paraná, Brazil. Herpetological Review, 93-94p. 2012. 


\title{
ABORDAGEM CLÍNICA E CIRÚRGICA DO COLAPSO TRAQUEAL EM CÃES
}

\author{
Bárbara Gonçalves BARBOSA.
}

E-mail de contato: barbosag.barbara@gmail.com

Introdução: $O$ colapso traqueal é uma afecção significativamente prevalente em cães de raça miniatura. Ele consiste na oclusão ou no estreitamento da traqueia em diferentes graus, os quais determinarão os sinais clínicos, tratamento e prognóstico do paciente. O avanço da tecnologia possibilitou o desenvolvimento de próteses de diversos tipos e materiais que, quando o manejo clínico não é mais suficiente, são capazes de promover qualidade de vida ao paciente através da intervenção cirúrgica.

Metodologia: esta revisão foi realizada a partir de buscas por trabalhos científicos no Google Acadêmico utilizando os termos "colapso traqueal" "manejo clínico" e "abordagem cirúrgica". O critério para a escolha dos trabalhos foram a clareza e a relevância das informações presentes.

Resultados: O tratamento conservador medicamentoso é adequado para boa parte dos animais acometidos pelo colapso traqueal, cerca de 65 a 78\%. Ele se baseia, essencialmente, no controle do peso (a partir da dieta e exercícios leves) e uma combinação de antitussígenos, anti-inflamatórios, corticoides, antibióticos e sedativos, variando de acordo com a necessidade de cada paciente. Indivíduos gravemente dispneicos devem ser internados com oxigenioterapia e sedação até a estabilização do quadro. Pacientes com redução do lúmen traqueal superior a $50 \%$, por sua vez, são candidatos ao tratamento cirúrgico para restaurar o diâmetro normal da traqueia. As técnicas cirúrgicas mais utilizadas atualmente consistem no uso de stents intraluminais e na colocação de próteses extraluminais. Em relação à colocação de próteses extraluminais e às cirurgias convencionais, a colocação de stents intraluminais é considerado um procedimento minimamente invasivo, feito com o auxílio da endoscopia e fluoroscopia. Os stents podem ser feitos com diferentes materiais, como plástico, silicone, metal ou serem híbridos. Podem ser classificados como autoexpansíveis ou de expansão do balão, e o tamanho do implante é estimado a partir da radiografia da traqueia do paciente. Para minimizar o risco de migração e encurtamento, o stent geralmente é cerca de 10 a 20\% maior do que a estenose. O tempo cirúrgico geralmente é curto, podendo chegar a poucos minutos de cirurgia, e a melhora na condição clínica é imediata. Em aproximadamente 28 a 33\% dos casos, ocorre a formação excessiva de tecido inflamatório no interior da traqueia, que leva a sinais de intolerância ao exercício e dificuldade respiratória. Este tecido pode ser removido com eletrocauterização ou ressecção a laser. A abordagem cirúrgica utilizando as próteses extraluminais são recomendadas quando o estreitamento se localiza na região cervical ou porção proximal da traqueia torácica. Nessa abordagem, é necessária a dissecação dos tecidos paratraqueais e sutura da prótese envolvendo o músculo traqueal. Um importante risco dessa cirurgia está relacionado à paralisia laríngea devido à lesão do nervo laríngeo recorrente durante o procedimento, podendo requerer uma traqueostomia permanente em alguns casos.

Conclusão: O colapso traqueal é uma afecção extremamente relevante na clínica médica e cirúrgica de cães. Dependendo do grau de comprometimento luminal, o tratamento de escolha pode ser clínico ou cirúrgico, visando sempre promover uma boa qualidade de vida ao paciente.

Palavras-chave: Colapso traqueal, Abordagem clínica, Correção cirúrgica 


\section{Referências:}

BECKER, W.M. et al. Survival after Surgery for Tracheal Collapse and the Effect of Intrathoracic Collapse on Survival. Veterinary Surgery, v. 41, n. 4, p. 501-506, 2012.

DURANT, A.M. et al. Use of nitinol stents for end-stage tracheal collapse in dogs. Veterinary Surgery, v. 41, n. 7, p. 807-817, 2012.

ETTINGER, S.J. et al. Doenças da Traqueia. In: Tratado de Medicina Interna Veterinária. 5. ed. Rio de Janeiro: [s.n.]. p. 1096-1112.

HAWKINS, E.C. Colapso da Traquéia. Rio de Janeiro: Elsevier, 2009. p. 279-80. In: Manual de medicina interna de pequenos animais. [s.l: s.n.]. p. 279-280.

JERRAM, R.M.; FOSSUM, T.W. Tracheal collapse in dogs. Compendium on Continuing Education for the Practicing Veterinarian. v. 19, n. 9, p. 1049-1060, 1997.

NELSON, R.W.; COUTO, C.G. Afecções da Traqueia e dos Brônquios. In: Manual de Cirurgia de Pequenos Animais. 3. ed. [s.l: s.n.]. p. 858-863.

RADLINSKY, M.G.; FOSSUM, T.W.; WALKER, M.A. et al. Evaluation of the Palmaz stent in the trachea and mainstem bronchi of normal dogs. Veterinary Surgery, v. 26, p. 99-107, 1997.

SUN, F. et al. Endotracheal stenting therapy in dogs with tracheal collapse. the Veterinary Journal, v. 175, p. 186-193, 2008.

WEISSE, C. Insights in tracheobronchial stenting and a theory of bronchial compression. Journal of Small Animal Practice, v. 55, p. 181-184, 2014. 


\title{
ACHADOS HISTOPATOLÓGICOS DE CINOMOSE EM GRAXAIM-DO- CAMPO (Lycalopex gymnocercus Fischer, 1814)
}

Andrea Moura DE CAMARGO; Aksa Ingrid Vieira BATISTA; Felipe José da Costa

ANDRADE; Gilmara Miguel SOUZA; Marina Neves de Assis AGUIAR; Jhonatan

Henrique Lima DA ROCHA; Raphaela Bueno Mendes BITTENCOURT; Gabriel Vinícius

\author{
Carvalho DE LUCENA.
}

E-mail de contato: andreamour.c@gmail.com

Introdução: O graxaim-do-campo (Lycalopex gymnocercus Fischer, 1814), também conhecido como raposa-dos-pampas, é um carnívoro de médio porte que ocorre na região Sul do Brasil. Essa espécie é categorizada pela International Union for Conservation of Nature Resources como Menos Preocupante (LC) e são relativamente tolerantes a distúrbios antrópicos, mantendo suas populações estáveis no Brasil. Entretanto, a sua aproximação em ambientes urbanos e periurbanos facilita o contato com canídeos domésticos, levando a transmissão de doenças, como a cinomose. Essa doença multissistêmica é causada por um Morbilivirus da família Paramixoviridae, que acomete principalmente os canídeos, sendo a espécie Lycalopex gymnocercus retratada como altamente susceptível, afetando principalmente seu sistema respiratório, gastrointestinal e sistema nervoso central (SNC), acarretando altas taxas de mortalidade. O diagnóstico pode ser realizado através de técnicas histopatológicas, além de outros exames. Dessa forma, o objetivo desse trabalho é a revisão dos achados histopatológicos de cinomose em graxaim-do-campo para diagnóstico da doença.

Metodologia: Foram pesquisados e baixados em torno de quatorze artigos nas línguas inglesa e portuguesa nas plataformas PubMed e Google Acadêmico sobre a cinomose em Lycalopex gymnocercus, bem como seus achados histopatológicos. Desses, foram escolhidos somente nove artigos, uma Tese de Conclusão de Curso (TCC), uma dissertação de mestrado e dois livros, levando em consideração apenas revisões de literatura e estudos que tratam sobre achados histopatológicos da cinomose em graxaim-do-campo e de canídeos domésticos, bem como características da espécie, compreendendo o período entre 1997 e 2020.

Resultados: Em técnicas de histopatologia realizadas nos indivíduos que apresentam a cinomose, é possível observar corpúsculos de inclusão eosinofílicos intracitoplasmáticos e/ou intranucleares, esses aparecem em epitélio bronquiolar, trato gastrointestinal e urinário, células epiteliais tegumentares, glândulas salivares e adrenais, ductos biliares, linfonodos, baço e Sistema Nervoso Central (SNC). As lesões encontradas no SNC pela técnica podem ser utilizadas como diagnóstico definitivo, sendo os astrócitos as células mais acometidas. Em um estudo feito por SLAVIERO M. (2016), foram identificadas principalmente lesões cerebelares, como a desmielinização, caracterizada por vacúolos, áreas de malácia associadas a altas quantidades de células de Gitter, astrócitos gemistocíticos, ocasionais manguitos perivasculares linfoplasmocitários e áreas multifocais de gliose. Essas lesões também podem ser observadas em nervos óticos, medulas oblonga e espinhal e meninges, além de astrocitose, astrogliose, células gigantes e infiltração de células mononucleares, intumescência e descamação de células meningeais. Em coxins plantares e plano nasal podem ser encontradas multiplicação viral nos queratinócitos, levando a hiperqueratose e paraqueratose. Conclusão: Conclui-se que a histopatologia é uma tecnica fundamental para diagnóstico da cinomose, possuindo achados principalmente no cerebelo. Sabendo que há poucos estudos sobre a doença em Lycalopex gymnocercus, esse trabalho contribui para revisar os principais 
achados de cinomose nessa espécie, assim colaborando com o diagnóstico clínico para fins de conservação.

Palavras-chave: Diagnóstico, Canídeos selvagens, Graxaim-do-campo.

Referências:

ARAÚJO, L.C. Investigação molecular da Infecção pelo Morbilivírus Canino em Espécies de Animais Silvestres do Estado de Mato Grosso. Dissertação de Mestrado. Universidade de Cuiabá. 2019.

CUBAS, Z.S.; SILVA J.C.R.; CATÃO-DIAS J.L. Tratado de Animais Selvagens. 2. ed. São Paulo: ROCA. 2014.

DEEM, S.L. et al. Canine distemper in terrestrial carnivores: a review. Journal of Zoo and Wildlife Medicine, v. 31, n. 4, p. 441-451, 2000.

GEBARA, C.M.S. et al. Lesões histológicas no sistema nervoso central de cães com encefalite e diagnóstico molecular da infecção pelo vírus da cinomose canina. Arquivo Brasileiro de Medicina Veterinária e Zootecnia, v. 56, n. 2, p. 168-174, 2004.

GREENE, C.E.; VANDEVELDE, M. Canine Distemper. In: GREEENE, C.E. Infectious Diseases of the Dog and Cat. 4. ed. St. Louis, Missouri: Elsevier, 2012, cap.3, p.25-42.

LECOUTEUR, R.A.; CHILD, G. Afecções da medula espinal. In: ETTTINGER, S. J.; FELDMAN, E.C. Tratado de Medicina Interna Veterinária. 4. ed. São Paulo: Manole Ltda, 1997, v. 1., cap. 83, p.890-980.

LÓPEZ, A. Sistema Respiratório. Bases da Patologia em Veterinária. 4. ed. Rio de Janeiro: Elsevier, 2009, cap. 9, p.463-558.

LUCHERINI, M. The IUCN Red List of Threatened Species. Lycalopex gymnocercus. 2016: e. T6928A85371194.

LUCHERINI, M.; VIDAL E.M.L. Lycalopex gymnocercus (Carnivora:Canidae). 2008. American Society Of Mammalogists. Mammalian Species, Issue 820.

MEGID, J. et al. Canine distemper virus in a crab-eating fox (Cerdocyon thous) in Brazil: case report and phylogenetic analyses. Journal of Wildlife Diseases, v.45, n.2, p. 527-530, 2009.

SLAVIERO M. Caracterização Patológica e Imuno-histoquímica de Cinomose em Graxain. 2016. Monografia. Setor de Patologia Veterinária (SPV). Universidade Federal do Rio Grande do Sul.

SLAVIERO M.; DRIEMEIER D. Achados patológicos e imuno-histoquímico de cinomose em graxaim-do-mato (Cerdocyon thous) e graxaim-do-campo (Lycalopex gymnocercus). 2016. Setor de Patologia Veterinária (SPV). Universidade Federal do Rio Grande do Sul. 
SWANGO, L. J. Moléstias virais caninas. In: ETTINGER, S. J.; FELDMAN, E.C. Tratado de Medicina Interna Veterinária. 4. ed. São Paulo: Manole Ltda, 1997. v. 1, cap. 69, p.573588.

ZACHARY, J.F. Sistema Nervoso. In: MCGAVIN, M. D.; ZACHARY, J. F. Bases da Patologia em Veterinária. 4. ed. Rio de Janeiro: Elsevier, 2009. cap. 14, p.833-971. 


\title{
CONHECIMENTO ATUAL DA MICROBIOTA EM TARTARUGAS MARINHAS
}

\author{
Gabriel da Silva FERREIRA; Luciana Gonçalves de OLIVEIRA; Vivian Chimendes da \\ Silva NEVES; Hugo Leonardo Rossiter Peixoto dos SANTOS; Michelline Lins \\ SILVÉRIO.
}

E-mail de contato: gabrielsilvaferreira@live.com

Introdução: Em todo o mundo há apenas sete espécies de tartarugas marinhas, pertencentes a seis gêneros. Cinco destas espécies, Caretta caretta, Chelonia mydas, Eretmochelys imbricata, Dermochelys coriacea e Lepidochelys olivacea utilizam o litoral brasileiro como rota para alimentação e reprodução. São animais que necessitam da migração durante sua vida, sempre à procura de ambientes que favoreçam sua sobrevivência e retornando para as praias que possuem as mesmas condições de onde nasceram. O corpo das tartarugas pode apresentar microrganismos que não causam danos ou são dispersos durante sua trajetória nos oceanos. Dentre esses microrganismos, os fungos podem ser oportunistas e se multiplicarem em organismos imunologicamente comprometidos. Conhecendo o risco de extinção associado às espécies, assim como os relatos de mortes por micoses, torna-se eminente a necessidade de incrementar pesquisas no âmbito da micologia em tartarugas marinhas. O objetivo desse trabalho foi identificar os avanços e as lacunas do conhecimento atual sobre a temática, reconhecendo a necessidade de maiores esforços e, assim, promovendo a conservação das tartarugas marinhas no Brasil e no mundo.

Metodologia: A coleta de dados ocorreu por meio das bases BVS, SciELO, Periódicos CAPES e Google Acadêmico. As palavras-chave utilizadas foram: "sea turtle, fungal infections, microbiology of the sea and marine turtle" (língua inglesa) e tartarugas marinhas, infecções fúngicas e microbiologia marinha (língua vernácula). Como critérios de inclusão foram considerados artigos publicados em periódicos nacionais e internacionais e que abordavam algum aspecto relacionado à ecologia de tartarugas marinhas nos últimos 10 anos - de 2010 a 2020.

Resultados: Inicialmente, foram listados 2.161 artigos, porém 33 atenderam aos critérios de inclusão. Destes, 25 selecionados se enquadraram nos métodos estipulados: 22 (88\%) corresponderam a pesquisas experimentais e $3(12 \%)$ a artigos de revisão, abrangendo globalmente os fungos e as tartarugas marinhas. Apesar do aumento mundial das pesquisas referentes às tartarugas marinhas, publicações que relatam sua interação com os fungos ainda são escassas. No total, 29 gêneros foram alvos de estudo, sendo Fusarium (21\%), Aspergillus $(11 \%)$ e Cladosporium (11\%) os mais frequentes, podendo estar presentes em todas as fases de desenvolvimento, desde ovo até adulto.

Conclusão: Estudos sobre a micota em tartarugas marinhas são escassos e necessitam de um conhecimento de possíveis patógenos que possam acometer os animais em todas as fases de sua vida.

Palavras-chave: Fungos oportunistas, quelônios marinhos, revisão de literatura. 


\section{Referências:}

GARCIA-HARTMANN, M.; HENNEQUIN, C.; CATTEAU, S.; BÉATINI, C.; BLANC, V. Cas groupés d'infection à Fusarium solani chez de jeunes tortues marines Caretta caretta nées en captivité. Journal de Mycologie Médicale, França, v. 27, n. 1, p. 113-118, 5 dez. 2016. DOI: https://doi.org/10.1016/j.mycmed.2016.12.001. Acesso em: 10 set. 2020.

GIL, A. C. Como elaborar projetos de pesquisa. 6. ed. Brasil: Atlas, 2017. p. 19.

IUCN. International Union for Conservation of Nature. Red List of Threatened Species.

Version 2020-2.

Disponível em: https://www.iucnredlist.org/search/map?taxonomies=100888\&searchType=species . Acesso em: 20 set. 2020.

MIGUEL, C. Tartarugas marinhas do Brasil e do mundo. Instituto Marcos Daniel: Projeto Chelonia mydas, 28 maio 2019. Disponível em: https://www.imd.org.br/singlepost/2019/05/27/Tartarugas-Marinhas-do-Brasil-e-do-Mundo. Acesso em: 18 set. 2020.

SIMÕES, T.N. et al. Ecoassociados e História de Conservação das Tartarugas Marinhas em Pernambuco. In: CORREIA, J. M. S.; SANTOS, E. M.; MOURA, G. J. B. (org.). Conservação de Tartarugas Marinhas no Nordeste do Brasil: Pesquisas, Desafios e Perspectivas. Recife/PE: Editora Universitária da UFRPE, 2016. cap. 6, p. 139 - 168. 


\title{
CORREÇÃO CIRÚRGICA DE URETER ECTÓPICO EM CÃES
}

\author{
Bárbara Gonçalves BARBOSA.
}

E-mail de contato: barbosag.barbara@gmail.com

Introdução: $\mathrm{O}$ ureter ectópico é uma anomalia congênita na qual um ou ambos os ureteres não se inserem na região do trígono vesical. A forma extramural ocorre quando o ureter é totalmente desviado da vesícula urinária e desemboca diretamente na uretra. Já a forma intramural, mais recorrente, ocorre quando o ureter atravessa a parede da vesícula urinária e falha em desembocar no trígono vesical. O sinal clínico mais comumente observado é a incontinência urinária desde o nascimento, geralmente associada a infecções urinárias recorrentes. O diagnóstico pode ser confirmado pela urografia excretora e o tratamento de escolha é a intervenção cirúrgica.

Metodologia: Esta revisão foi realizada através de buscas por trabalhos científicos na plataforma Google Acadêmico utilizando os termos "ureter ectópico em cães" e "correção cirúrgica". O critério para a escolha dos trabalhos foram a clareza e a relevância das informações presentes.

Resultados: Embora a maioria dos pacientes com ureter ectópico apresentem incontinência urinária e quadros recorrentes de cistite e pielonefrite, animais que apresentam micção dentro dos padrões de normalidade não devem ter esse diagnóstico prontamente excluído, pois muitas vezes a ectopia é unilateral ou a abertura do ureter é próxima ao trígono vesical, provocando poucos sinais clínicos. O diagnóstico diferencial consiste principalmente em doenças que podem levar ao quadro de incontinência urinária, como cálculo uretral, desordens neurológicas e insuficiência primária do esfíncter. $\mathrm{O}$ tratamento de escolha é a correção cirúrgica e deve ser implementado o mais breve possível, a fim de se evitar o acometimento renal. Atualmente diferentes técnicas têm sido empregadas, como a neoureterostomia, a ureteroneocistostomia e a ablação a laser, sendo que a última é realizada com menor frequência devido à necessidade de equipamentos e treinamento avançados, e a escolha entre as duas primeiras é feita de acordo com a localização do ureter. A neouretrostomia é indicada para a correção cirúrgica de ureter ectópico intramural. Essa intervenção consiste em criar a abertura do ureter na região do trígono vesical e ocluir a parte do ureter ectópico que se desloca para a uretra. Já a neoureterocistostomia é indicada para pacientes que apresentam ureter ectópico extramural, túnel da submucosa do ureter ectópico intramural de difícil localização ou ureter intramural localizado cranialmente ao trígono. Neste procedimento o ureter é ligado e seccionado o mais próximo possível da vesícula urinária, em seguida é tracionado para dentro da nova abertura vesical e adequadamente fixado. Quando há comprometimento renal, a ureteronefrectomia pode ser indicada desde que o rim contralateral esteja funcional, pois consiste na remoção, em bloco, do rim e ureter. Conclusão: $O$ ureter ectópico é uma anomalia congênita de grande relevância na medicina canina. É de suma importância que seu diagnóstico seja realizado o mais breve possível, bem como sua correção cirúrgica, sendo que a técnica deve ser escolhida de acordo com a anatomia da alteração. Quando tratado precoce e corretamente, as chances de melhora da qualidade de vida do paciente com a redução da incontinência urinária e das infecções recorrentes são significativas.

Palavras-chave: Ureter ectópico, Cães, Correção cirúrgica 


\section{Referências:}

COSTA NETO, J.M. et al. Ectopia ureteral em cães: relato de dois casos. Arquivos de Ciências Veterinárias e Zoologia da Unipar, Umuarama, v. 14, n. 2, p.151-156, dez. 2011.

MACPHAIL, Catriona M.. Cirurgia de rim e ureter. In: FOSSUM, Theresa Welch. Cirurgia de Pequenos Animais. 4. ed. Rio de Janeiro: Elsevier, 2014. p. 2002- 2085.

MATHEWS, Kyle. Ureters. In: A JOHNSTON, Spancer; TOBIAS, Karen M. Veterinary Surgery Small Animal. 2. ed. Athens: Elsevier, 2018. p. 5954-6002.

MCLOUGHLIN, M.A.; CHEW, D.J. Diagnosis and Surgical Management of Ectopic Ureters. Clinical Techniques In Smallammal Practice. Columbus, v. 15, n. 1, p.17-24, fev. 2000 .

STONE E, A.; MANSON, L. Surgery of ectopic ureters: types, method of correction, and postoperative results. Journal Of The American Animal Hospital Association, Raleigh, v. 26, n. 1, p.81-88, jan. 1990.

TANEY, K.G.; MOORE, K.W.; CARRO, T.; SPENCER, C. Bilateral ectopic ureters in a male dog with unilateral renal agenesis. Scientific Reports: Clinical Report, Norwalk, v. 223 , n. 6 , p.817-820, set. 2003. 


\title{
DIAGNÓSTICO ULTRASSONOGRÁFICO DE CISTITE EM FÊMEA DE PORQUINHO DA ÍNDIA (Cavia porcellus)
}

\author{
Délcio Almeida MAGALHÃES; Victor Coelho PAVAN; Sofia Silva La Rocca de
} FREITAS; Mariana Vargas Ferreira de REZENDE; Felipe José da Costa ANDRADE.

E-mail de contato: delciomagalhaes2000@gmail.com

Introdução: Os roedores são cada vez mais frequentes na rotina clínica de animais de companhia, sendo suas principais afecções relacionadas ao seu manejo, que muitas vezes é executado de forma errônea. Os problemas de trato urinário são muitas vezes correlatos ao manejo, porém podem ser idiopáticos, configurando um maior desafio ao clínico de pets não convencionais. O presente trabalho tem por objetivo, descrever o diagnóstico ultrassonográfico de cistite em fêmea de Porquinho-da-Índia (Cavia porcellus) atendido em um hospital veterinário no estado de São Paulo.

Metodologia: Um indivíduo fêmea de Porquinho-da-índia (Cavia porcellus) foi admitido em um hospital veterinário particular da cidade de Guarujá-SP com histórico de polidipsia, poliúria e urina de tom branco. Durante a anamnese e exame físico não foram notadas demais alterações. A principal suspeita clínica foi de cálculos vesicais, bastante comuns em roedores. Foi optado pelo exame de ultrassonografia abdominal para a visualização de possíveis cistites, nefropatias ou até possíveis alterações reprodutivas. Segundo Peng (1990), as fêmeas de C.porcellus apresentam uma maior predisposição à afecções como a cistite e urolitíase, sendo relacionadas com infecções por Escherichia coli e Staphylococcus sp, diabetes mellitus e à anatomia do sistema urogenital feminino desta espécie, em que o ânus se localiza muito próximo da uretra, facilitando a entrada de bactérias intestinais pelo canal uretral.

Resultados: Durante o exame ultrassonográfico da cavidade abdominal, foi possível perceber um leve espessamento de parede de vesícula urinária e uma alta quantidade de sedimentação, compatívelDe Todas com maior concentração urinária, e com pouca celularidade. De acordo com Lavelle (1998) a cistite pode ser causada por infecções ou danos químicos ao epitélio do sistema urinário ou das camadas subjacentes em casos de cistites hemorrágicas. É presumido que durante a cistite haja uma alteração na permeabilidade da parede da bexiga por conta da inflamação que leva a descamação das células epiteliais, resultando em um vazamento de substâncias nocivas da urina às camadas subjacentes da parede da bexiga. Foi optado pelo tratamento conservativo com uma mudança dietética, com introdução de fitoterápicos como a cranberry, rica em proantocianidina, que impede translocação bacteriana para a vesícula urinária e mudanças como redução de alimentos verdes escuros ricos em ácido oxálico e cálcio, como couve, brócolis, espinafre, salsinha e hortelã, além do estímulo maior à ingestão hídrica.

Conclusão: Foi possível observar que o tratamento utilizado apresentou bons resultados com remissão dos sinais referentes a cistite. Espera-se ainda que os dados encontrados nesse trabalho possam ser usados como ferramentas para diagnóstico ultrassonográfico de cistite em Cavia porcellus. 
Referências:

LEWIS, S.A.; BERG, J.R.; KLEINE, T.J. Modulation of epithelial permeability by extracellular macromolecules. Physiological reviews, v. 75, n. 3, p. 561-589, 1995.

LAVELLE, J.P.; APODACA, G.; MEYERS, S.A.; RUIZ, W.G.; ZEIDEL, M.L. Disruption of guinea pig urinary bladder permeability barrier in noninfectious cystitis. American Journal of Physiology-Renal Physiology, v. 274, n. 1, p. 205-214, 1998.

PENG, X.; GRIFFITH, J.W.; LANG, C.M. Cystitis, urolithiasis and cystic calculi in ageing guinea pigs. Laboratory animals, v. 24, n. 2, p. 159-163, 1990.

SANT, G.R.; KEMPURAJ, D.; MARCHAND, J.E.; THEOHARIDES, T.C. The mast cell in interstitial cystitis: role in pathophysiology and pathogenesis. Urology, v. 69, n. 4, p. 34-40, 2007.

PIMENTA, Y.T.S.; SEGALA, R.D.; PITA, M.C.G.; SALZEDAS, B.A.; LOPES, D.M.; DOS SANTOS, S.O.; CANGUSSU, R.B. Urolitíase em Porquinho-da-Índia (Cavia porcellus): Relato de Caso. PUBVET, v. 13, p. 148, 2019.

YOSHIDA, M.; SAITO, T. Non-urotoxic induction of hemorrhagic cystitis by braxin C, a bracken toxin, in guinea pigs. The Journal of toxicological sciences, v. 19, n. 2, p. 55 59, 1994.

KIM, Y.S.; LEVIN, R.M.; WEIN, A.J.; LONGHURST, P.A. Effects of sensitization on the permeability of urothelium in guinea pig urinary bladder. The Journal of urology, v. 147, n. 1, p. 270-273, 1992.

ZAPATA, J. L.; DEL SOL, M.; VÁSQUEZ, B. Estereología renal en el Cobayo (Cavia porcellus). International Journal of Morphology, v. 27, n. 2, p. 420-424, 2009. 


\title{
DIETA DE ANTAS (Tapirus terrestris LINNAEUS, 1758) E A IMPORTÂNCIA PARA A DISPERSÃO DE SEMENTES EM TERRITÓRIO NACIONAL - REVISÃO SISTEMÁTICA
}

\author{
Gilmara Miguel SOUZA; Felipe José da Costa ANDRADE; Jhonatan Henrique Lima DA \\ ROCHA; Gabriel Vinícius Carvalho DE LUCENA; Raphaela Bueno Mendes \\ BITTENCOURT; Andrea Moura DE CAMARGO; Aksa Ingrid Vieira BATISTA; Marina \\ Neves de Assis AGUIAR.
}

E-mail de contato: gilmarasouzamiguel@gmail.com

Introdução: As antas (Tapirus terrestris ACOSTA et al., 2013) são os maiores mamíferos terrestres do país, pertencem à família Tapiridae à ordem Perissodactyla. Este animal é listado como vulnerável à extinção pela União Internacional para a Conservação da Natureza e dos Recursos Naturais, sendo a caça predatória, os atropelamentos e a destruição de seu habitat as principais ameaças para a espécie. Apresentam grande importância ambiental para a dispersão de sementes e reflorestamento, principalmente na região da mata atlântica. Este trabalho tem como intuito revisar os hábitos alimentares e a importância das antas para a dispersão de sementes.

Metodologia: Esta revisão sistemática é composta por dados coletados durante o mês de setembro de 2020, através das plataformas digitais Google Acadêmico e SciELO. Foram consultados 12 artigos e livros publicados ou editados entre os anos de 2000 e 2020, em português e inglês. Após o levantamento de dados, 1 livro, 2 revistas e 3 teses sobre biologia e comportamento de animais silvestres e ecologia foram selecionados para compor a base técnica-informacional deste trabalho.

Resultados: De acordo com Mangini et al. (2010), a dieta de Tapirus terrestris pode ser constituída de 33 a 34,5\% de frutas e entre 65,5 a 66\% por folhas e outras fibras, sendo grandes responsáveis pela dispersão das sementes dos vegetais que consomem. Além disso, em estudo realizado por Zorzi e colaboradores (2009), foi registrado que as concentrações dos componentes coletados nas fezes destes mamíferos e os índices de fertilidade das sementes varia de acordo com a região em que o animal vive. Segundo Dias et al. (2006), quando ocorre rompimento de tegumento ou emergência de radículas das sementes anteriormente à dispersão, estas são consideradas germinadas e, quando ocorre ressecamento ou quebra da estrutura da semente, deve-se classificá-las como sementes predadas. Ademais, em estudo realizado durante 14 meses entre 2008 e 2009, por Silveira et al. (2010) constatouse que entre 49 defecações analisadas, 32,6\% continham 6 espécies diferentes de vegetais e, 11 dessas amostras foram depostas sobre a água, enquanto as demais, foram colhidas em morros, encostas e vales, o que permite analisar as diferentes probabilidades de germinação. No mesmo estudo, percebeu-se que durante o verão a deposição de bolos fecais na natureza é demasiadamente elevada se comparada com às demais estações do ano, quando se investe o mesmo intervalo de tempo para coleta. Além disso, em trabalho realizado por Pol e colaboradores (2012), constata que entre 13 amostras fecais colhidas em Bertioga, foram encontradas sementes de 45 espécies diferentes e através de análises de germinação de morfoespécie, ao menos $25 \%$ dos vegetais ingeridos pelos mamíferos obtiveram sucesso de dispersão.

Conclusão: Conclui-se que a alimentação de T. terrestris varia de acordo com o local em que vivem e, com a variabilidade do habitat, os índices de sucesso na dispersão de sementes 
podem divergir entre as regiões do país. Além disso, é perceptível a importância das antas para o reflorestamento em território nacional, de acordo com os resultados obtidos. Dessa forma, estudos como este incentivam a conservação das antas no Brasil, através do reconhecimento do papel ambiental desses mamíferos.

Palavras-chave: Conservação, Tapiridae.

\section{Referências:}

BUENO, R. S. Frugivoria e efetividade de dispersão de sementes dos últimos grandes frugívoros da Mata Atlântica: a anta (Tapirus terrestris) e o muriqui (Brachyteles arachnoides). 69 f. Dissertação (mestrado) - Universidade Estadual Paulista, Instituto de Biociências de Rio Claro, 2010.

CUBAS, Z.S.; SILVA, J.C.R.; CATÃO DIAS, J.L. Tratado de Animais Selvagens. 2. ed. São Paulo: Roca, 2014.

FRAGOSO, J.M.V.; HUFFMAN, J.M. Seed-dispersal and seedling recruitment patterns by the last Neotropical megafauna element in Amazônia, the Tapir. Journal of Tropical Ecology, Cambridge, v. 16, p. 369-385, 2000.

GALETTI, M. et al. Frugivory and Seed Dispersal by the Lowland Tapir (Tapirus terrestris) in Southeast Brazil. Biotropica, Washington, v. 33, n. 4, p. 723-726, 2001.

TÓFOLI, C.F. Frugivoria e dispersão de sementes por Tapirus terrestris (Linnaeus, 1758) na paisagem fragmentada do Pontal do Paranapanema, São Paulo. 2006.

ZORZI, B. Frugivoria por Tapirus terrestres em três Regiões do Pantanal, Brasil. 64p. Universidade Federal do Mato Grosso do Sul, Campo Grande, 2009. 


\section{DIVERSIDADE ALIMENTAR DA DIETA DE Myrmecophaga tridactyla e Tamandua tetradactyla DE VIDA LIVRE NO BRASIL - REVISÃO SISTEMÁTICA}

Felipe José da Costa ANDRADE; Andrea Moura de CAMARGO; Jhonatan Henrique Lima da ROCHA; Gabriel Vinícius Carvalho de LUCENA; Gilmara Miguel SOUZA; Aksa Ingrid Vieira BATISTA; Marina Neves de Assis AGUIAR; Raphaela Bueno Mendes BITTENCOURT.

E-mail de contato: felipevet14@gmail.com

Introdução: Os tamanduás são pertencentes à superordem xenarthra, juntamente com os tatus e as preguiças. Diferindo-se entre 9 espécies, no Brasil as mais conhecidas e estudadas são o tamanduá-bandeira e o tamanduá-mirim. Essas espécies se dividem de hábito de vida terrestre e semi-arborícola, respectivamente. Sua alimentação é especializada em grande parte em cupins e formigas. Estudos referentes a diversidade alimentar desses animais ainda é escassa, visto que, poucos estudos abordam gêneros e espécies de formigas e cupins na alimentação desses animais. Posto isto, o objetivo desse trabalho é revisar a diversidade de cupins e formigas consumidos por Myrmecophaga tridactyla e Tamandua tetradactyla de vida livre no território brasileiro, a fim de contribuir para o estudo alimentar desses animais.

Metodologia: Este trabalho constitui uma revisão sistemática. A coleta de dados foi realizada entre agosto e setembro de 2020, utilizou-se para a pesquisa as bases de dados Scientific Eletronic Library Online e Google Acadêmico. Foi definido como critério de inclusão artigos publicados entre os anos de 2000 até 2020, além de trabalhos com desenvolvimento no Brasil. Foram selecionados 3 artigos e 1 tese de doutorado, onde apresentaram conhecimento sobre o tema.

Resultados: Em trabalho com Tamandua tetradactyla, Ferreira et al. (2007), encontrou uma grande quantidade de formigas $(77,5 \%)$ em contrapartida a cupins $(22,5 \%)$. Além disso, encontrou 12 gêneros de formigas da Família Formicidae, sendo eles Acanthognathus, Acromyrmex, Aenictus, Camponotus, Cerapachys, Crematogaster, Leptogenys, Linepithema, Pachycondyla, Pheidole, Solenopsis e Zacryptocerus, sendo que o gênero Solenopsis foi o mais encontrado. Santos et al. (2008), em seu estudo com Tamandua tetradactyla, encontrou uma quantidade parecida entre cupins e formigas, as formigas do gênero Camponotus foram as mais encontradas (24,75\%), seguido de Paratrichina (6,30\%), Acromyrmex (3,20\%), Solenopsis (2,67\%), Pheidole (2,07\%), Brachymyrmex (0,14\%), Hypocryptocerus (0,03\%) e tribo Ponerini (0,03\%). Em seu estudo com Myrmecophaga tridactyla no pantanal, Medri et al. (2003), observou que os animais consumiram proporção elevada de formigas (81\%) em relação de cupins (19\%). Solenopsis interrupta foi a espécie de formiga mais encontrada (36\%), em seguida de, Solenopsis saevissima (36\%), Solenopsis pusillignis (5\%), Camponotus crassus (7\%), Camponotus renggeri (5\%), Solenopsis invicta (5\%), Ectatomma planidens (2\%), Labidus spininodis (2\%) e Odontomachus minutus (2\%). Em relação a de cupins, foi encontrado Nasutitermes coxipoensis e Armitermes sp. No estudo com tamanduá-bandeira, Braga (2010) compara a frequência de formigas (73,7\%) e cupins $(26,3 \%)$ encontradas na dieta desses animais em vida livre. Sendo que, formigas do gênero Camponotus apresentaram alta frequência (87,5\%), seguido de Acromyrmex crassispinus (83,3\%), Atta (79,1\%), Solenopsis (75\%), Pheidole (73,9\%), Odontomachus (26,1\%) e Ectatomma (4,3\%). Além disso, foram encontradas formigas do gênero Forelius c.f. e Labidus. Os gêneros de cupins encontrados foram Nasutitermes (91,6\%) e Syntermes (79,1\%). Além disso, uma única cabeça de Neocapritermes foi encontrada nas amostras. 
Conclusão: Poucos estudos estão disponíveis em relação a diversidade de espécies de cupins e formigas encontradas em tamanduás de vida livre. Além disso, as espécies encontradas apresentaram valores variados, que pode ser explicado pelas diferentes disponibilidades de alimentos em relação ao habitat. Estudos futuros devem ser realizados para descrever mais espécies de cupins e formigas na alimentação desses animais. Espera-se que esse estudo possa servir de parâmetro para manejo nutricional de tamanduás ex situ.

Palavras-chave: Xenarthra, Mamíferos, Insetos.

\section{Referências:}

BRAGA, F.G. Ecologia e Comportamento de Tamanduá-Bandeira Myrmecophaga Tridactyla Linnaeus, 1758 No Município De Jaguariaíva, Paraná. Tese (Doutorado) Universidade Federal do Paraná, Setor de Ciências Agrárias. Programa de Pós-Graduação em Engenharia Florestal - Conservação da Natureza. Curitiba, 2010.

CUBAS, Z.S.; SILVA, J.C.R.; CATÃO-DIAS, J.L. Tratado de animais selvagens. 2.ed. São Paulo: Roca, 2014.

FERREIRA, A.C.; CALDATO, N.; FILHO, W. R.; IEDE, E. T. Composição da dieta de tamanduá mirim (tamandua tetradactila). Evento De Iniciação Científica Da Embrapa Florestas, 6., Colombo. Anais. Colombo: Embrapa Florestas, 2007.

MEDRI, I.M.; MOURÃO, G.M.; HARADA, A.Y. Dieta de Tamanduá-Bandeira (Myrmecophaga tridactyla) no Pantanal da Nhecolândia, Brasil. Edentata no. 5. December 2003.

SANTOS, F.; REIS FILHO, W.; ROCHA, V.J. Diversidade de formigas (Hymenoptera, Formicidae) em dieta alimentar de tamanduá-mirim (Tamandua tetradactyla). In: Evento De Iniciação Científica Da Embrapa Florestas, 7., 2008, Colombo. Anais. Colombo: Embrapa Florestas, 2008. 


\title{
DIVERSIDADE ENDOPARASITÁRIA EM VEADO-CAATINGUEIRO (MaZama gouazoubira FISCHER, 1814) EM TERRITÓRIO NACIONAL - REVISÃO SISTEMÁTICA
}

\author{
Aksa Ingrid Vieira BATISTA; Jhonatan Henrique Lima DA ROCHA; Andrea Moura DE \\ CAMARGO; Raphaela Bueno Mendes BITTENCOURT; Gilmara Miguel SOUZA; Felipe \\ José da Costa ANDRADE; Marina Neves de Assis AGUIAR; Gabriel Vinícius Carvalho \\ DE LUCENA.
}

E-mail de contato: aksaingridmv@gmail.com

Introdução: O veado-catingueiro (Mą̧ama gonazoubira FISCHER, 1814) é uma espécie de cervo da ordem Artiodactyla e família Cervidae. São um dos menores cervídeos, pesando em média $18 \mathrm{~kg}$ e com altura da cernelha geralmente em torno dos $50 \mathrm{~cm}$. Possuem uma coloração do cinza-escuro ao marrom avermelhado, muitas vezes possuindo uma pinta branca acima dos olhos. Essa é a espécie mais predominante de cervídeo na América do Sul, em diversos tipos de habitat, se localizando desde o Uruguai até o norte do Mato Grosso, e desde a cordilheira dos Andes até o Oceano Atlântico. É ruminante, herbívoro e sua dieta consiste em folhas, frutos e brotos. As endoparasitoses estão entre as principais afecções que acometem animais silvestres de vida livre e de cativeiro, podendo influenciar a sobrevivência e reprodução do hospedeiro, e alterar suas taxas de natalidade e mortalidade, o que é um obstáculo para a conservação. No entanto, muitos desses animais podem albergar uma grande quantidade de parasitos, inclusive zoonóticos, e não apresentarem sinal algum de doença parasitária. Assim sendo, a finalidade desse trabalho é revisar a diversidade de endoparasitos em M. gouazoubira, para contribuir com dados da espécie em questão.

Metodologia: Cerca de 14 artigos foram baixados na plataforma Google Acadêmico e PubMed em inglês e português sobre parasitologia em animais silvestres e parasitos em cervídeos. Desses, apenas 8 artigos e um livro foram selecionados, levando em consideração a espécie escolhida (Mazama gonazoubira) e a caracterização do parasito em no mínimo gênero. Resultados: Os protozoários coccídeos encontrados foram Eimeria spp. (Coccidia: Eimeriidae) em Santa Catarina, Brasil; Cryptosporidium parvum (Coccidia: Cryptosporiidae) no estado do Rio Grande do Sul; e Cystoisospora sp. (Coccidia: Sarcocystidae) no estado da Paraíba. Protozoários intraeritrocíticos assim como Theileria sp. e Theileria cervi (Apicomplexa: Piroplasmida) também foram encontrados em amostras de sangue coletadas da referida espécie em Minas Gerais. Alem disso, trofozoítos do flagelado Giardia sp. (Fornicata: Diplomonadida) foram encontrados em espécimes de vida livre no estado de São Paulo. O único Trematoda relatado foi Paramphistomum spp. (Digenea:Plagiorchiida) no estado de Santa Catarina. Os nematóides achados para essa espécie foram o Trichinellida Capillaria bovis (Capillaridae); os Rhabditida Physocephalus lassancei, Pygarginema verrucosa (Spirocercidae) os Strongylida Bunostomum phlebotomum (Ancylostomatidae); Cooperia punctata, Haemonchus contortus, Haemonchus similis, T. axei (Trichostrongylidae), sendo todos esses na região do Pantanal, e Trichostrongylus spp. na Paraíba.

Conclusão: Esse trabalho contribui para a compilação referente aos dados ecológicos, bem como para a conservação de M. gouzazoubira. A partir desse estudo, será possível que mais trabalhos sejam realizados com o objetivo de compreender a bioecologia desses parasitos em veados-catingueiros e investigar as consequências que estes venham a causar e interferir no bem-estar da espécie. 
Palavras-chave: Cervídeos, Mammalia, Parasitologia.

Referências:

CUBAS, Z.S.; SILVA, J.C.R.; CATÃO-DIAS, J.L.; Tratado de Animais Selvagens. 2. ed. São Paulo: ROCA, 2014.

DA SILVEIRA, J.A.G. et al. Detection of Theileria and Babesia in brown brocket deer (Mazama gouazoubira) and marsh deer (Blastocerus dichotomus) in the State of Minas Gerais, Brazil. Veterinary parasitology, v. 177, n. 1-2, p. 61-66, 2011.

DA SILVEIRA, J.A.G. et al. Post-mortem hemoparasite detection in free-living Brazilian brown brocket deer (Mazama gouazoubira, Fischer 1814). Revista Brasileira de Parasitologia Veterinária, v. 23, n. 2, p. 206-215, 2014.

DE OLIVEIRA, S.G. et al. Prevalência de Bertiella sp. em um grupo de bugios-pretos, Alouatta caraya (Humbolt, 1812). A Primatologia no Brasil, 2011.

HOLSBACK, L. et al. Natural infection by endoparasites among free-living wild animals. Revista Brasileira de Parasitologia Veterinária, v. 22, n. 2, p. 302-306, 2013.

LUX HOPPE, E.G. et al. Helminthological screening of free-ranging grey brocket deer Mazama gouazoubira Fischer, 1817 (Cervidae: Odocoileini) from Brazilian Pantanal wetlands, with considerations on Pygarginema verrucosa (Molin, 1860) Kadenatzii, 1948 (Spirocercidae: Ascaropsinae). Brazilian Journal of Biology, v. 70, n. 2, p. 417-423, 2010.

MARQUES, S.M.T. et al. Parasitos gastrintestinais de veados (Mazama gouazoupira) de áreas nativas no planalto de Santa Catarina, Brasil. Vet Foco, v. 5, p. 3-9, 2007.

REGINATTO, A.R. et al. Report of cryptosporidiosis in gray brocket deer (Mazama gouazoupira) in southern Brazil. Comparative clinical pathology, v. 19, n. 5, p. 523-525, 2010 .

SILVA, M.I.S. et al. Ascaropsinae (Alicata \& Mcinstoch, 1993) parasites of deer from the lowlands region of the state of Mato Grosso do Sul, Brazil. Rev Bras Parasitol Vet, v. 8, n. 2, p. 133-136, 1999. 


\title{
ENRIQUECIMENTO AMBIENTAL COM CHRYSOCYON BRACHYURUS EM CATIVEIRO
}

\author{
Lilian Silva CATENACCI, Marília Gabryelle Guimarães DE MACÊDO, Felipe José Da \\ Costa ANDRADE, Anne Valéria Costa ALVES, Italo CRESPI, Ionara Silva DE SOUSA.
}

E-mail de contato: mariliamacdo@outlook.com

Introdução: Existem diversas estratégias com o propósito de estimular comportamentos presentes na natureza em animais sob cuidados humanos. A junção dessas estratégias é conhecida como enriquecimento ambiental (EA), que tem por intenção promover o estado de bem-estar dos animais, elevando dessa forma, a complexidade do ambiente atuando na diminuição de comportamentos estereotipados e tempo ocioso. O EA pode ser cognitivo, alimentar, sensorial, físico e social. O presente trabalho teve como objetivo observar a responsividade aos enriquecimentos ambientais do tipo sensorial e alimentar do Lobo-guará (Chrysocyon brachyurus) mantido em uma baia para cuidados médicos no Hospital Veterinário Universitário da Universidade Federal do Piauí campus Bom jesus - PI após ser encontrado ferido na Estação Ecológica de Uruçuí-Una pelo ICMBIO.

Metodologia: Foram utilizadas três técnicas de EA em um período de 15 dias durante agosto e setembro de 2019, sendo todas elas inseridas pela manhã após a alimentação regular e observadas por um tempo médio de 30 minutos. A primeira oferecida foi o picolé de frutas feito com bananas, tomates, cajus e maçãs imersas em água e congeladas; para a segunda forma de enriquecimento alimentar utilizou-se 1 abóbora, a qual foi cortada na superfície e retirado seu conteúdo para introduzir o recheio, feito de ração e carne; e a última foi o enriquecimento sensorial com a utilização do pó de canela espalhado pelo recinto do animal. Resultados: A partir da oferta dos enriquecimentos foram observados a aceitação e a interação do animal em relação a cada um. Com o picolé de frutas, o animal interagiu imediatamente após ter sido oferecido, refrescando-se, entretanto, deixou sobras de frutas. Já com a abóbora o animal passou o intervalo de 5 a 10 minutos demonstrando interesse e alimentou-se de todo o recheio, porém não comeu a abóbora inteira, que era grande. A dispersão da canela em pó - feita sem exageros para evitar excesso de aspiração e efeitos adversos, teve o intuito de estimular o sentido olfativo do lobo-guará, que reagiu imediatamente andando e cheirando por todo o recinto dentro do período de observação de 30 minutos. Os tipos de EA utilizados foram o sensorial e alimentar, uma vez que para um animal debilitado seria inviável investir em EA físico, cognitivo e/ou social. O animal respondeu positivamente aos três procedimentos, no entanto pode-se destacar o uso da canela em pó que obteve um excelente aproveitamento pela interação ter sido instantânea e duradoura, em segundo destacou-se a abóbora recheada pois o animal interagiu bem restando apenas uma parte da abóbora. Já o picolé de frutas, apesar da interação ter sido imediata, várias frutas não foram ingeridas pelo animal, caracterizando uma interação satisfatória, porém a menos proveitosa das três técnicas utilizadas.

Conclusão: Todos os métodos tiveram um baixo custo financeiro visto que foram utilizados ingredientes bastante acessíveis. Dessa maneira, técnicas de EA podem se tornar uma opção viável ao tratar-se do bem-estar pois apresentam um papel relevante no processo de reabilitação de animais em cativeiro, diminuindo os níveis de estresse em razão do confinamento.

Palavras-chave: alimentar, Chrysocyon brachyurus, sensorial 


\section{Referências:}

COUTINHO, P.H.M. Enriquecimento Alimentar e Cognitivo para o Bem-Estar em Cativeiro. 2012. 80 f. Dissertação (Mestrado) - Curso de Medicina Veterínaria, Núcleo de Teoria e Pesquisa do Comportamento, Universidade Federal do Pará, Belém, 2012. Disponível em: <http://www.repositorio.ufpa.br/jspui/bitstream/2011/5339/1/Dissertacao_Enriquecim entoAlimentarCognitivo.pdf $>$. Acesso em: 10 set. 2019.

OLIVEIRA, P.K.M.; CARPI, L.C.F.G. Enriquecimento ambiental para ariranha (Pteronura brasiliensis) no zoológico de Brasília. 2016. Disponível em: <http://www.revistaseletronicas.fmu.br/index.php/ASA/article/view/1155/1052>. Acesso em: 09 set. 2019.

VASCONCELLOS, A.S. O estimulo ao forrageamento como fator de enriquecimento para lobos guarás: efeitos comportamentais e hormonais. 2009. 137 f. Tese (Doutorado) - Curso de Psicologia, Instituto de Psicologia, Universidade de São Paulo, São Paulo, 2009. Disponível em: <https://www.teses.usp.br/teses/disponiveis/47/47132/tde-30112009095524/publico/TESE_DOUTORADO.pdf>. Acesso em: 06 set. 2019. 


\title{
CAUSAS MORTIS EM PSITTACIFORMES NO BRASIL: UMA REVISÃO SISTEMÁTICA
}

\author{
Raphaela Bueno Mendes BITTENCOURT; Jhonatan Henrique Lima da ROCHA; Marina \\ Neves de Assis AGUIAR; Felipe José da Costa ANDRADE; Gilmara Miguel SOUZA; \\ Aksa Ingrid Vieira VIEIRA; Andrea Moura DE CAMARGO; Gabriel Vinícius Carvalho \\ DE LUCENA.
}

\section{E-mail de contato: rafabmbitt@gmail.com}

Introdução: O Brasil é destaque mundial na biodiversidade de Psittaciformes (SICK, 1997), por ter o maior número de representantes dessa ordem (PRESTI et al. 2006), que segundo a IUCN (International Union for Conservation of Nature), possui a maior soma de espécies ameaçadas dentro das aves. Ter conhecimento das principais causas de morte auxilia na prevenção, controle e tratamento de doenças (CUBAS, 1996) em um contexto de medicina da conservação. Esse trabalho objetiva trazer um levantamento das causas mortis de psitacídeos no Brasil nos últimos quinze anos.

Metodologia: Foi realizada uma pesquisa bibliográfica em setembro de 2020, por produções científica, utilizando os bancos de dados on-line do Google Scholar, Periódicos Cappes e no PubMed. Foram utilizadas as seguintes palavras-chave em português e inglês: Morte (Death), Psittacidae e Brasil (Brazil). Para inclusão do trabalho ele deveria constar nos bancos de dados utilizados, serem de acesso gratuito, estar compreendido no período de 2005 a 2020 e relatar a causa de morte. Dentre os artigos pesquisados 19 foram encontradas no Brasil, sendo que 10 foram excluídos por não relatarem a causa de morte e 01 por ser revisão de literatura. Dentre os 08 artigos restantes as causas de morte foram agrupadas em doenças parasitarias, infecciosas, predação e neoplasias.

Resultados: Foram coletados ao todo dados de 102 animais da ordem Psittaciformes. A principal causa mortis levantada foram as doenças infecciosas que somaram $71,57 \%$ das responsáveis por óbitos em psitacídeos. No estudo de Murer et al. (2020) quatro óbitos de Psittacula krameri, foram relatados, por herpesvírus e provável infecção secundária por Aspergillus sp e Candida sp. Segundo Corrêa e colaboradores (2013) oito espécimes de Amazona pretrei morreram por Colibacilose. Bezerra et al. (2016) relatou óbito de onze indivíduos da espécie Anodorbynchus byacinthinus de vida livre por pododermatite bacteriana e consequente sepse. De acordo com Murer (2018), cinquenta indivíduos de Platycercus sp e Psephotus haematonotus, morreram devido a infecção por Avipoxvirus. As mortes por doenças parasitárias resultaram em 14,71\% dos casos levantados. Segundo Teodoro et al. (2018) o trematódeo Paratanaisia bragai, foi responsável pelo óbito de um Psittacara leucophthalmus. Outro parasita causador de óbito foi a Ascaridia hermafrodita, segundo relato de Melo (2013), 14 psitaccídeos, morreram pela obstrução intestinal parasitária. A predação de sete ninhegos de Aratinga aurea (PARANHOS et al. 2008) somou 6,86\% de participação como causa mortis. As neoplasias representaram 6,86\% das mortes de psitacídeos, com seis óbitos por linfoma, colangiocarcinoma, colangioma e hemagiossarcoma, relatadas em Amazona Aestiva e uma morte de Melopsittacus undulatus por carcinoma renal primário (GODOY et al. 2009) Os resultados apresentados excluem importantes fatores envolvidos na morte desses animais como o tráfico, colisões, caça, entre outros (MATUSHIMA et al. 2006).

Conclusão: Existem poucos relatos de óbitos de Psitaciformes, comunicar a morte e investigar a causa mortis é importante para a vida animal e para a conservação, por trazer à 
luz problemas que merecem a atenção e mostrar um panorama epidemiológico. A necropsia é uma ferramenta acessível, que permite a identificação da causa de óbito e seu registro.

Palavras-chave: Óbito, Medicina da Conservação, Medicina Veterinária Legal.

Referências:

BEZERRA, K.S.; ROSA, J.M.A.; WITTER, R.; FERREIRA, L.P.; GUEDES N.M.R.; RASO, T.F.; COLODEL, E.M. Surto de mortalidade em araras-azuis (Anodorhynchus hyacinthinus) no pantanal matogrossense, Brasil, associado à pododermatite necrótica: Achados morfológicos. [Dissertação] Mato Grosso: Universidade Federal do Mato Grosso, Faculdade de Agronomia e Medicina Veterinária, 2016.

CORRÊA, I.M.O. et al. Detecção de fatores de virulência de Escherichia coli e análise de Salmonella spp. em psitacídeos. Pesquisa Veterinária Brasileira, v. 33, n. 2, p. 241-246, 2013.

CUBAS, Z.S. Special challenges of maintaining wild animals in captivity in South America. Revue scientifique et technique. International Office of Epizootics, v. 15, p. 267-87, 1996.

GODOY, S.N. et al. Principais processos neoplásicos encontrados em psitacídeos mantidos em cativeiro. Pesquisa Veterinária Brasileira, v.29, n. 6, p. 445-451. 2009.

MATUSHIMA, E.R. Técnicas Necroscópicas. In: Cubas, Z.S.; Silva J.C.R; Catão-Dias J.L. Tratado de animais selvagens. São Paulo: Roca, p. 980-990, 2006.

MELO, C.M.F. et al. Parasites of Psittaciformes and Accipitriformes in Paraíba state, northeastern Brazil. Rev. Bras. Parasitol. Vet, v. 22, n. 2, p. 314-317, 2013.

MURER, L. Psittacid herpesvirus 3 infection in roseringed parakeets in southern Brazil. Journal of Veterinary Diagnostic Investigation, v. 32, n. 3, p. 409-412, 2020.

MURER, L. et al. Identification and phylogenetic analysis of clade $\mathbf{C}$ Avipoxvirus in a fowlpox outbreak in exotic psittacines in southern Brazil. Journal of Veterinary Diagnostic Investigation, v. 30, n. 6, p. 946-950, 2018.

PARANHOS, S. J; Araújo, C.B.de; Machado, L.O.M. Comportamento reprodutivo de Aratinga aurea (Aves, Psittacidae) no sudoeste de Minas Gerais, Brasil. Revista Brasileira de Ornitologia, v. 16, n. 1, p. 1-7, 2008.

PRESTI, F.T.; MIYAKI, C.Y. Caracterização da variabilidade genética em espécies de psitacídeos ameaçados. [Dissertação] São Paulo: Universidade de São Paulo, Instituto de Biociências, 2006.

SICK, H. Ornitologia Brasileira. 2. ed. Rio de Janeiro: Nova Fronteira. 1997.

TEODORO, T.G.W. et al. Varaschin. Psittacara leucophthalmus (Aves: Psittacidae) como um novo hospedeiro de Paratanaisia bragai (Trematoda: Eucotylidae) no 
Brasil: achados clínicos e patológicos: relato de caso. Arq. Bras. Med. Vet. Zootec., v. 70, n. 5, p. 1569-1576, 2018. 


\section{PRINCIPAIS PLATELMINTOS QUE ACOMETEM ARRAIAS DO GÊNERO Potamotrygon - REVISÃO SISTEMÁTICA}

Gabriel Vinícius Carvalho DE LUCENA; Aksa Ingrid Vieira BATISTA; Marina Neves de Assis AGUIAR; Felipe José da Costa ANDRADE; Gilmara Miguel SOUZA; Raphaela Bueno Mendes BITTENCOURT; Andrea Moura DE CAMARGO; Jhonatan Henrique Lima DA ROCHA.

E-mail de contato: gabrielviniciuslucenac@gmail.com

Introdução: As arraias do gênero Potamotrygon pertencem a família Potamotrygonidae, sendo os únicos representantes dos elasmobrânquios adaptados a viverem exclusivamente em água doce. Esses animais possuem modificações anatômicas como atrofia da glândula retal; comportamentais, como o cuidado parental; e fisiológicas, como a busca pela superfície para ventilação em águas paradas. Os potamotrygonídeos possuem distribuição geográfica em águas continentais da América do Sul, sendo que no Brasil é encontrada a maior densidade de espécies. Dentre as principais patologias encontradas em peixes, as parasitoses são comumente relatadas, sendo os parasitos pertencentes ao Filo Platyhelminthes de alta prevalência em arraias continentais. Estes ganham destaque pelo potencial zoonótico, assim representando risco para a saúde única, e influenciando na biologia desses animais, se mostrando um obstáculo para a conservação. Deste modo, o objetivo do presente trabalho é revisar as principais espécies de platelmintos encontrados parasitando arraias do gênero Potamotrygon.

Metodologia: Foram consultados 24 artigos disponíveis na plataforma Google Acadêmico e PubMed, nos idiomas inglês, espanhol e português sobre parasitos em arraias do gênero Potamotrygon. Desses, apenas 9 artigos foram selecionados, levando em consideração a caracterização do parasito em no mínimo gênero.

Resultados: Dentre os Cestoda, os parasitos da ordem Rhinebothriidea e família Rhinebothriidae relatados no gênero de arraias Potamotrygon foram: Rhinebotbrium corbatai e Rhinebothrium mistyae em P. motoro na Argentina; Rhinebothroides venezuelensis e Rhinebothroides mclennanae na mesma espécie em Mato Grosso do Sul, Brasil; Rbinebothrium paratrygoni em $P$. motoro no mesmo local e em P. falkneri no rio Paraná deste mesmo país; e por fim Rhinebothrium moralarai em $P$. magdalenae na Colômbia. Já na ordem Tetraphyllidea e família Onchobothriidae foram encontrados os parasitos Acanthobothrium regoi e Potamotrygonocestus travassosi em P. falkneri para o rio Paraná, Brasil; A. ramiroi em P. motoro nos afluentes do mesmo rio na Argentina; Potamotrygonocestus orinocoensis também para esta espécie no Mato Grosso do Sul, Brasil; e Potamotrygonocestus magdalenensis em P. magdalenae para a Colômbia. E na ordem Trypanorhyncha foi achado o parasito Paroncomegas araya (Eutetrarhynchidae) em P. falkneri para o rio Paraná, Brasil. Já na classe Trematoda foram relatados os parasitos Clinostomum complanatum (Strigeidida: Clinostomidae), Tylodelphys sp. (Diplostomida: Diplostomidae) e Genarchella sp. (Hemiuroidea: Derogenidea) em P.falkneri para rios tributários do rio Paraná na Argentina. E por fim, os Monogenea da ordem Monocotylidea e família Monocotylidae descritos foram Potamotrygonocotyle quadracotyle e Potamotrygonocotyle umbella em Potamotrygon sp.; Potamotrygonocotyle rarum em P. schroederi; e Potamotrygonocotyle rionegrense em P. motoro. Quanto à ordem Hexabothriidea e família Hexabothriidae foi relatado o parasito Paraheteronchocotyle amažnense em P. orbignyi, sendo todos estes monogeneos para a região da Amazônia, Brasil. 
Conclusão: Esse trabalho colabora com a ampliação referente aos dados ecológicos, bem como para conservação deste referido gênero. A partir desse estudo, será possível que pesquisas futuras sejam realizadas com a finalidade de compreender a bioecologia desses parasitos em arraias continentais, e deste modo investigar as consequências que as populações desses indivíduos podem sofrer e como a relação parasito-hospedeiro interfere no bem-estar desses animais.

Palavras-chave: Helmintos, Elasmobrânquios, Parasitologia.

Referências:

ARAÚJO, M. et al. Freshwater stingrays (Potamotrygonidae): status, conservation and management challenges. Information document AC. v. 20, p. 1-6, 2004.

BROOKS, D.R.; THORSON, T.B. Dois cestóides tetrafilidianos da arraia de água doce Potamotrygon magdalenae Dumeril 1852 (Chondrichthyes: Potamotrygonidae) da Colômbia. The Journal of parasitology, p. 943-947, 1976.

BROOKS, D.R.; AMATO, J.F.R. Cestode parasites in Potamotrygon motoro (Natterer)(Chondrichthyes: Potamotrygonidae) from southwestern Brazil, including Rhinebothroides mclennanae n. sp.(Tetraphyllidea: Phyllobothriidae), and a revised host-parasite checklist for helminths inhabiting neotropical freshwater stingrays. The Journal of parasitology, p. 393-398, 1992.

DOMINGUES, M.V. et al. Monogenoidean parasites of freshwater stingrays (Rajiformes: Potamotrygonidae) from the Negro River, Amazon, Brazil: species of Potamotrygonocotyle (Monocotylidae) and Paraheteronchocotyle (Hexabothriidae). Folia Parasitologica, v. 54, n. 3, p. 177, 2007.

GARRONE NETO, D. et al. Registro de ocorrência de duas espécies de potamotrigonídeos na região do Alto Rio Paraná e algumas considerações sobre sua biologia. Biota Neotropica. vol. 7, n. 1, p. 205-208, 2007.

IVANOV, V.A. A new species of Acanthobothrium (Cestoda: Tetraphyllidea: Onchobothriidae) from the ocellate river stingray, Potamotrygon motoro (Chondrichthyes: Potamotrygonidae), in Argentina. Journal of Parasitology, v. 91, n. 2, p. 390-396, 2005.

LACERDA, A.C.F. et al. Ecology of endoparasites of the fluvial stingray Potamotrygon falkneri (Chondrichthyes: Potamotrygonidae) from the upper Paraná River floodplain, Brazil. Brazilian Journal of Biology, v. 69, n. 2, p. 297-303, 2009.

MENORET A.; IVANOV V. A. Descrições de duas novas espécies neotropicais de água doce de Rhinebothrium (Cestoda: Rhinebothriidea) de Potamotrygon motoro (Chondrichthyes: Potamotrygonidae). Folia Parasitologica, v. 58, p. 178-186, 2011.

MENORET, A.; IVANOV, V.A. A new species of tetraphyllidean (Cestoda) from the Largespot river stingray, Potamotrygon falkneri (Potamotrygonidae: Chondrichthyes), from the Paraná Basil. Journal of Parasitology, v. 95, n. 4, p. 994-999, 2009. 


\title{
REAÇÃO VACINAL EM FERRET: RELATO DE CASO
}

\author{
Délcio Almeida MAGALHÃES; Victor Coelho PAVAN; José Manuel Pedreira \\ MOURIÑO.
}

E-mail de contato: delciomagalhaes2000@gmail.com

Introdução: $\mathrm{Na}$ clínica de pets não convencionais os ferrets são uma realidade muito frequente, tornando necessário maior conhecimento acerca de suas afecções e medicina preventiva. Entre as vacinas recomendadas estão as contra o vírus da raiva e o da cinomose. Porém, atualmente no Brasil, não existem vacinas específicas para ferrets e muitas destas vacinas voltadas para outros carnívoros domésticos podem contribuir com possíveis reações vacinais. Alguns dos sintomas comuns são desde enjôos simples até convulsões em casos mais graves. O objetivo deste trabalho é elucidar a importância do acompanhamento e planejamento da imunização de ferrets uma vez que as particularidades fisiológicas devem ser respeitadas durante as abordagens clínicas.

Materiais e métodos: Um indivíduo macho de 3 anos da espécie Mustela putorius furo foi atendido em uma clínica veterinária particular na cidade de São Paulo com o intuito de realizar a vacinação anual para o vírus da cinomose. A única vacina recomendada para a espécie no país é voltada para cães e ferrets e imuniza também contra o vírus da parvovirose canina. Este tipo de vacina costuma causar reações adversas comuns nos ferrets. Para evitar uma possível reação vacinal mais grave, 20 minutos previamente à imunização foi administrado dexametasona $0,2 \mathrm{ml}$ de forma intramuscular. Ao ser vacinado o paciente apresentou prostração, êmese e hematoquezia em poucos minutos após a vacinação. Uma das possibilidades dos acontecimentos de reações vacinais em ferrets são as possíveis intolerâncias aos adjuvantes presentes e no veículo, como por exemplos antibióticos.

Resultados: $O$ animal recebeu tratamento suporte, com ondansetrona $1 \mathrm{mg} / \mathrm{kg}$ intramuscular, dipirona com escopolamina $(0,1 \mathrm{ml}$ de forma subcutânea) e oxigenioterapia. Após 2 horas o ferret recebeu alta clínica devido a remissão dos sintomas. A vacinação de ferrets contra doenças como a raiva e a cinomose é fundamental pelo caráter mortal destas afecções porém a falta de uma vacina específica para a espécie pode levar os pacientes à reações que segundo Greenacre (2003) consistem de choques anafiláticos, com hiperemia, hipersalivação e vômito, podendo evoluir para quadros de dispnéia, diarréia e hematoquezia. Moore (2005) indica que existe um fator cumulativo por trás das vacinas da cinomose, onde a chance de ocorrerem reações adversas aumenta em até $80 \%$ a cada vacinação. Wade (2018) recomenda a administração via oral de difenidramina previamente à aplicação e em casos de sintomas adversos o tratamento deve ser realizado com a administração de dexametasona e epinefrina.

Conclusão: Vacinar os ferrets contra a raiva e a cinomose é imprescindível, porém é fundamental o acompanhamento dos indivíduos após a aplicação das vacinas pois existe a possibilidade de ocorrerem reações adversas danosas ao animal.

Palavras-chave: Ferrets; Imunização; Clínica. 
Referências:

GREENACRE, C.B. Incidence of adverse events in ferrets vaccinated with distemper or rabies vaccine: 143 cases (1995-2001). Journal of the American Veterinary Medical Association, v. 223, n. 5, p. 663-665, 2003.

WADE, L.L. Vaccination of Ferrets for Rabies and Distemper. Veterinary Clinics: Exotic Animal Practice, v. 21, n. 1, p. 105-114, 2018.

MOORE, G. et al. Incidence of and risk factors for adverse events associated with distemper and rabies vaccine administration in ferrets. Journal of the American Veterinary Medical Association, v. 226, n. 6, p. 909-912, 2005.

WIMSATT, J. et al. Serologic evaluation, efficacy, and safety of a commercial modified-live canine distemper vaccine in domestic ferrets. American Journal of Veterinary Research, v. 62, n. 5, p. 736-740, 2001.

WELTER, J. et al. Vaccination against canine distemper virus infection in infant ferrets with and without maternal antibody protection, using recombinant attenuated poxvirus vaccines. Journal of virology, v. 74, n. 14, p. 6358-6367, 2000.

HOOVER, J.P.; BALDWIN, C.A.; RUPPRECHT, C.E. Serologic response of domestic ferrets (Mustela putorius furo) to canine distemper and rabies virus vaccines. Journal of the American Veterinary Medical Association, v. 194, n. 2, p. 234-238, 1989. 


\title{
RELATO DE CASO DE FRATURA POR DOENÇA OSTEOMETABÓLICA EM FILHOTE DE JAGUATIRICA (LEOPARDUS PARDALIS Linnaeus, 1758)
}

\author{
Raphaela Bueno Mendes BITTENCOURT; Luciana Batalha de Miranda ARAÚJO.
}

\section{E-mail de contato: rafabmbitt@gmail.com}

Introdução: Os felinos silvestres estão dentre as espécies mais ameaçadas do mundo, por serem predadores no topo da cadeia alimentar (FRANCO et al. 2018). Há pouca informação disponível sobre a eficiência com a qual as jaguatiricas utilizam os nutrientes de suas presas (BENNETT et al. 2013), e em filhotes as informações são ainda mais escassas, as recomendações nutricionais são extrapoladas de felinos domésticos, o que as torna pouco confiáveis.

As doenças osteometabólicas são frequentes em animais silvestres mantidos em cativeiro. Caracterizadas pela perda de massa óssea, ocasionando a fragilidade e consequentemente fraturas (MONTAGNANI, 2014). A deficiência de vitamina D é uma causa de raquitismo e osteomalácia (MECHICA, 2006; SILVA et al. 2008). Em gatos domésticos o fêmur é o osso que mais sofre lesões devido ao hábito de escalada, representando cerca de $30 \%$ de todas as fraturas (DAL-BÓ et al. 2013). Nas jaguatiricas os ossos longos, como o fêmur, estão expostos a grande impacto. O objetivo deste trabalho é relatar a ocorrência de fratura completa de epífise femoral em um exemplar filhote de L. pardalis mantida em cativeiro e com deficiência de calcificação óssea.

Metodologia: Em dezembro de 2018, uma jaguatirica, fêmea de 6 meses de idade, foi encaminhada pelo Centro de Triagem de Animais Silvestre (CETAS) de Goiás, para o Hospital Veterinário da Universidade Federal de Goiás, com suspeita fratura de fêmur, após queda de baixa altura. Foi realizada a avaliação clínica e hemograma. O paciente foi encaminhado para radiografia do membro posterior direito, foi feita uma imagem ventrodorsal de pelve e uma látero-lateral.

Resultados: Na radiografia foi possível visualizar fratura completa de fêmur direito, fechada, em diáfise proximal, transversa e simples. Pela imagem foi possível perceber comprometimento ósseo relacionado a doença osteometabólica prévia, com redução de opacidade óssea, osteopenia generalizada, diminuição de mineralização cortical e trabecular, epífises com linhas de mineralização irregulares. O hemograma apresentou trombocitose, aumento no hematócrito e diminuição na hemoglobina, e aumento das proteínas plasmáticas totais indicando hemoconcentração por desidratação, anisocitose moderada e presença de acantócitos. O leucograma apresentou linfocitose. Bioquímica com aumento da ALT. A fratura observada, em conjunto com as imagens radiográficas, histórico e avaliação clínica do paciente são indicativos de deficiência de aposição de matriz mineral, provável raquitismo, sendo a deficiência de vitamina $\mathrm{D}$ a causa mais provável devido ao manejo em seu tempo de cativeiro. Foi realizado um procedimento cirúrgico para a correção da fratura, com a inserção de placa de metal. E monitoramento da consolidação óssea posterior. Durante o procedimento cirúrgico, devido a doença osteometabólica, houve grande dificuldade na estabilização do pino no tecido ósseo, que estava muito fino, dificultando o procedimento. A preocupação nesse caso, não é apenas a cicatrização da ferida e reconstituição do tecido ósseo fraturado, mas também a correta formação óssea e articular de todo organismo.

Conclusão: Diante da descrição apresentada permite-se concluir a importância do manejo nutricional adequado ao se lidar com espécimes vulneráveis à extinção, além da necessidade de dados sobre aporte nutricional e correto manejo indicado para espécie em cativeiro. 
Palavras-chave: Felino Silvestre, Radiografia, Vitamina D.

\section{Referências:}

BENNET, C.L.; BOOTH-BINCZIK S.D.; STEELE S.R.E.; Nutritional composition and digestibility by ocelots (Leopardus pardalis) of whole animals and a commercial diet. Zoo Biol, v.29, n. 6, p. 753-9, 2010.

DAL-BÓ Í.S. et al. Osteossíntese de fémur em gato-do-mato-pequeno (leopardus tigrinus). Pesquisa Vet. Bras., v. 33, n. 3, p. 389-93, 2013.

FRANCO, J.L.A.; DRUMMOND, J.A.L; NORA, F.P.M. History of science and conservation of the jaguar (Panthera onca) in Brazil. Hist Ambient Latinoam y Caribeña Rev la Solcha, v. 8, n. 2, p. 42-72, 2018.

MECHICA, J.B. Raquitismo e osteomalacia. Arq Bras Endocrinol Metabol, v. 3, n. 6, p. 457-466, 2006.

MONTAGNANI, A. Bone anabolics in osteoporosis: Actuality and perspectives. World J. Orthop. v. 5, n. 3, p. 247, 2014.

SILVA, B.C.C. Prevalência de deficiência e insuficiência de vitamina $\mathbf{D}$ e sua correlação com PTH, marcadores de remodelação óssea e densidade mineral óssea, em pacientes ambulatoriais. Arq Bras Endocrinol Metabol, v. 52, n. 3, p. 482-488, 2008. 


\title{
SINDROME DA BEXIGA NATATÓRIA - REVISÃO DE LITERATURA
}

\author{
Saul Mota BEZERRA; Isadora Martins dos Santos AMORIM; Isadora Bessa Miranda \\ ANDRADE; Mariana Almeida BRITO; SILVA, Micaely Barbosa de Oliveira SILVA; \\ Seldon Almeida de SOUZA.
}

E-mail de contato: saulbezerra10@gmail.com

Introdução: A síndrome da bexiga natatória refere-se a uma variedade de problemas que afetam a bexiga natatória dos peixes. Esse órgão auxilia o animal a se manter na profundidade pelo controle da densidade deles em relação à da água. O objetivo deste trabalho foi realizar uma revisão de literatura sobre essa enfermidade que por se tratar de uma doença de maior prevalência nos aquários ainda não é muito relatada pois a clínica de peixes se encontra em ascensão no Brasil.

Metodologia: A bexiga natatória é um saco de paredes flexíveis que pode se expandir ou contrair de acordo com a pressão possuindo poucos vasos sanguíneos (MILLER,1996). Esse órgão permite que o peixe mantenha sua posição na água (BALDISSEROT, 2002). A síndrome da bexiga natatória ocorre quando esse órgão para de funcionar, fazendo com que o animal perca o equilíbrio e tenha dificuldade para flutuar. $\mathrm{Na}$ maioria das vezes essa condição ocorre quando se tem uma compressão no órgão estando associado a uma indistinção do estômago por um consumo excessivo de ração ou excesso de fermentação devido ao desbalanceamento da flora intestinal tendo-se então um acúmulo de gases. Bactérias e fungos também podem estar associados a essa enfermidade. Tumores e lesões no rim, podem provocar um deslocamento unilateral da bexiga natatória ocasionando a síndrome e em casos mais graves pode-se ocorrer o rompimento desse órgão. Os quadros clínicos são percebidos quando o animal perde o equilíbrio fazendo com que ele fique de cabeça para baixo ou de lado e não conseguindo flutuar de forma normal (SMITH, 2019). O animal ainda pode apresentar um abdômen distendido e costas curvas devido a constipação e perda de apetite. O diagnóstico pode ser realizado através de exames como ultrassonografia, radiografia e tomografia computadorizada (SMITH, 2019). O tratamento é estabelecido quando se descobre a causa da doença. Pode-se adicionar sal e aumento da temperatura do aquário para acelerar o metabolismo do animal, ser feito também uma restrição alimentar de 2 a 3 dias, caso seja necessário deve ser usado antibióticos e medicamentos que aumentem a motilidade gastrointestinal.

Resultados: No Brasil, o aquarismo é uma prática que vem crescendo muito e é preciso estar atento ao manejo dos animais, para que não sofram com doenças como a síndrome da bexiga natatória. Apesar de ser uma doença conhecida por quem cria peixes, são necessários cuidados específicos para o tratamento desses animais pois em algumas espécies esse órgão atua como pulmão, mostrando então sua importância anátomo-fisiológica para a sobrevivência desses animais. Acredita-se também que essa enfermidade esteja relacionada com uma mudança no canal medular (WEBER, 2014), porém mais estudos devem ser realizados.

Conclusão: A clínica de peixes apesar de ainda pequena, tem ocupado um lugar de destaque no interesse dos médicos veterinários, devido a maior preocupação que os proprietários vêm demonstrando com o mesmo. Tornando-se necessário um estudo maior acerca das enfermidades que esses animais podem desenvolver pois referências à clínica de peixes não são facilmente encontradas. 
Palavras-chave: Bexiga, Aquarismo, Clínica.

Referências:

BALDISSEROT, B. Fisiologia de peixes aplicada a piscicultura. 1. ed. São Paulo: Editora UFSM, 2002.

MILLER, P.J. British Small Animal Veterinary Association. Manual of Ornamental Fish. 2. ed. Editora: Wiley, 1996, p. 154-167.

SMITH, S.A. Fish Diseases and Medicine.1. ed. Editora: CRC Press, 2019.

WEBER, E.S. A Veterinary Guide to the Fish Gastrointestinal Tract. Veterinary Clinics of North America Exotic Animal Practice v. 17, n. 2, p. 123-143, 2014. 


\title{
TÉCNICAS DE ENRIQUECIMENTO AMBIENTAL PARA LOBOS- GUARÁ (Chrysocyon brachyurus ILLIGER, 1815) EX SITU - REVISÃO SISTEMÁTICA
}

\author{
Dafne Elias KLEFTAKIS; Karine Zargidsky MARQUES; Marina Neves de Assis \\ AGUIAR; Roberta Margato de ANDRADE; Thor Véras Teixeira LEÔNCIO; Ayla \\ Fernanda de Souza RODRIGUES.
}

\section{E-mail de contato: dafne.kleftakis@gmail.com}

Introdução: $\mathrm{O}$ enriquecimento ambiental tem como objetivo melhorar a qualidade de vida dos animais silvestres mantidos em cativeiro, proporcionando, através de diversas técnicas, um ambiente onde esses animais possam realizar suas necessidades etológicas, diminuindo o tempo ocioso e aumentando a diversidade comportamental. Este trabalho teve por objetivo apresentar técnicas de enriquecimento ambiental para lobos-guará em cativeiro, e descrever o impacto dessas técnicas no comportamento desses animais. Chrysocyon brachyurus é o maior canídeo sul-americano, é um animal tímido, solitário, onívoro e possui hábitos noturnos, tendo seu pico de atividade no período crepuscular (SOUZA, 2000).

Metodologia: Para esta revisão sistemática, utilizou-se as plataformas online Google Scholar e Scientific Eletrônic Library Online, em setembro de 2020, filtrando os termos "enriquecimento ambiental", "Chrysocyon brachyurus", "ex situ" e "lobos-guará", procurando literaturas nos idiomas inglês e português, publicadas entre os anos de 2000 e 2019. Foram selecionados 8 trabalhos, dentre eles, duas dissertações, um trabalho de conclusão de curso, uma tese e três artigos publicados em revistas. Portanto, foram selecionados artigos com base em técnicas de enriquecimento ambiental que causaram efeitos comportamentais positivos em lobosguará.

Resultados: Segundo Cummings et al. (2007), a população ex situ de Chrysocyon brachyurus não é autossustentável em virtude da má reprodução e incompetência parental. Estudos demonstram que técnicas de enriquecimento ambiental promovem comportamentos parentais naturais em animais de cativeiro e análises comportamentais indicam efeitos positivos em lobos-guará ex situ. Após observações feitas em quatro zoológicos, Ricci et al (2019) propôs técnicas de enriquecimento que consistiam em esconder alimentos em bolas de cipó ou espalhados pelos recintos, com temperos de cheiro forte, estimulando esses animais a explorar, mantendo-os ativos e evitando comportamentos estereotipados. Vasconcellos (2009) estudou enriquecimento alimentar em onze lobos-guará. Foram utilizados alimentos dentro de caixas de papelão, bolas de cipó, sacos de tecido ou ráfia, tubos de PVC e alimentos escondidos na vegetação rasteira ou nas copas das árvores. Observou-se efeitos positivos, como aumento na interação com o ambiente enriquecido, aumento no forrageamento e redução do pacing. Figueira (2014) analisou estímulos olfativos como enriquecimento ambiental para cinco Chrysocyon brachyurus. Foram colocados carne moída, queijo, urina de roedor e ovo cozido em sacos permeáveis, permitindo que os animais tivessem acesso apenas ao odor desses alimentos. Os estímulos foram atrativos e provocaram resposta comportamental positiva nos animais, como tentar pegar e farejar os sacos, brincadeiras, interação social e automanutenção. Alves (2007) observou e avaliou os efeitos do enriquecimento alimentar e sensorial em um casal de lobos-guará, utilizando frutas, ovos crus, picolés de carne, presas vivas, bolas, ossos defumados e cocô verde com carne em seu interior. Durante o enriquecimento houve diminuição na inatividade, através de locomoção, exploração e forrageamento. 
Conclusão: Conclui-se que para manter esses animais em cativeiro com a finalidade de conservação e pesquisa, assegurando a qualidade de vida e perpetuação da espécie, é necessário proporcionar um ambiente onde esses indivíduos possam praticar seu comportamento natural a partir de técnicas de enriquecimento ambiental, espera-se que possam ser utilizadas as estratégias de enriquecimento citadas neste trabalho. São necessários estudos futuros para confirmar a exatidão dos dados e resultados obtidos.

Palavras-chave: Canídeo, Comportamento, Estímulos.

Referências:

ALVES, G.B. Enriquecimento comportamental de lobo-guará (Chrysocyon brachyurus) em cativeiro. $30 \mathrm{f}$. Trabalho de Conclusão de Curso (Graduação em Ciências Biológicas) - Universidade Federal de Uberlândia, Uberlândia, 2007.

AZEVEDO, C.S.; BARÇANTE, L. Enriquecimento ambiental em zoológicos: em busca do bem-estar animal. Revista Brasileira de Zoociências, v. 19, n. 2, 2018.

CUMMINGS, D. et al. Behavioral and physiologic responses to environmental enrichment in the maned wolf (Chrysocyon brachyurus). Zoo Biology: Published in affiliation with the American Zoo and Aquarium Association, v. 26, n. 5, p. 331-343, 2007.

VASCONCELLOS, A.S. et al. O estímulo ao forrageamento como fator de enriquecimento ambiental para lobos guarás: efeitos comportamentais e hormonais. Tese de Doutorado. Universidade de São Paulo (USP). Instituto de Psicologia, 2009.

SOUSA, L.R. Chrysocyon brachyurus: ecologia e comportamento do Lobo-guará. Monografia (Ciências Biológicas) - Faculdade de Ciências da Saúde, Centro Universitário de Brasília, 2000.

VASCONCELLOS, A.S. et al. Environmental enrichment for maned wolves (Chrysocyon brachyurus): group and individual effects. Animal Welfare, v. 18, n. 3, p. 289-300, 2009.

FIGUEIRA, M.P. et al. Estímulos olfativos como enriquecimento ambiental em raposa-do-campo (Lycalopex vetulus), cachorro-do-mato (Cerdocyon thous), loboguará (Chrysocyon brachyurus) e cachorro doméstico (Canis lupus familiaris) (Carnivora, Canidae). Dissertação de Pós-graduação (Biologia Animal) - Universidade Federal de Viçosa, 2014.

FUKUSHIMA, A.R. et al. COMPARATIVE ANALYSIS OF THE BEHAVIOR OF THE LOBO-GUARÁ (CHRYSOCYON BRACHYURUS) IN CAPTIVEIRO: A PROPOSAL FOR ENVIRONMENTAL ENRICHMENT. Revinter - Revista Inertox de Toxicologia, Risco ambiental e Sociedade, v. 12, n. 2, p. 32, 2019. 


\title{
UTILIZAÇÃO DA CRIOPRESERVAÇÃO ESPERMÁTICA APLICADA NA PRESERVAÇÃO DE GRANDES CARNÍVOROS - REVISÃO SISTEMÁTICA
}

\author{
Jhonatan Henrique Lima DA ROCHA; Felipe José da Costa ANDRADE; Gilmara Miguel \\ SOUZA; Gabriel Vinícius Carvalho DE LUCENA; Raphaela Bueno Mendes \\ BITTENCOURT; Andrea Moura DE CAMARGO; Aksa Ingrid Vieira BATISTA; Marina \\ Neves de Assis AGUIAR.
}

E-mail de contato: jhonatan.lug@gmail.com

Introdução: Grandes carnívoros compõem um extenso número de espécies ameaçadas de extinção, sendo as ações antrópicas o fator principal dessa problemática. Atividades como desmatamentos, queimadas e caça furtiva contribuem significativamente para a perda de habitat desses animais, resultando na redução populacional desses seres vivos. Para minimizar os danos ocasionados por essas ações e garantir o sucesso da conservação dessas espécies, faz-se o uso de biotecnologias reprodutivas, dentre essas, destacam-se a criopreservação de gametas, possibilitando o manejo genético de populações em centros de reprodução, zoológicos e parques. Dessa forma, objetiva-se por esse resumo analisar as aplicações e resultados da criopreservação em algumas espécies de carnívoros, relatados nos principais trabalhos área.

Metodologia: Foram consultados 25 artigos disponíveis na plataforma Google Acadêmico, SciELO, PubMed e periódicos (Portal da CAPES), nos idiomas inglês, espanhol e português sobre biotecnologias reprodutivas aplicadas na conservação de animais silvestres. Desses, apenas 5 artigos e um livro foram selecionados, priorizando os estudos mais atuais, de 2000 até 2020.

Resultados: Segundo Silva et al. (2004) usa-se como modelo os protocolos experimentais de cães e gatos para a adaptação de técnicas voltadas para grandes carnívoros, além disso, dentre as maiorias das técnicas prioriza-se o uso principalmente de amostras do gameta masculino. O método mais utilizado para a coleta de sêmen é a eletroejaculação, entretanto, estudos atuais utilizam novas formas de coleta, Teodoro et al. (2012), usou o mecanismo de manipulação digital em seu estudo e obteve sucesso ao coletar sêmen em lobos-guará (Chrysocyon brachyurus). Já Maksudov et al. (2008) aplicou a recuperação epididimária, método que consiste em recuperar espermatozóides de indivíduos que vieram a óbito, ou passaram por esterilização, dentre as espécies coletadas temos como exemplo o urso andino (Tremarctos ornatos), puma (Puma concolor) e onça-pintada (Panthera onca), porém, a qualidade da amostra é em sua maioria comprometida devido às condições da coleta, que são realizadas em grande parte em animais senis ou mortos. Por fim, Araújo et al. (2017), desenvolveu um método farmacológico utilizando substâncias anestésicas derivadas da medetomidina, em que ocorre a ejaculação sem a necessidade de estímulos elétricos, ao qual obteve-se excelentes resultados em onças-pintadas preconizando a dose de 0,08 a $0,1 \mathrm{mg} / \mathrm{kg}$. Após a coleta é preciso que sêmen seja preparado para a criopreservação, assim aplica-se meios diluidores para suprir as necessidades espermáticas e evitar alterações deletérias durante o processo. Dentre os vários diluidores testados, de acordo com Silva et al. (2018), os que tem em sua composição Tris(hidroximetil)-aminometano obtiveram maior sucesso em espécies carnívoras. Amstislavsky et al., (2012), afirma em seu trabalho que outros componentes são fundamentais para a complementação do meio diluidor, dentre os componentes destaca-se a gema de ovo, usada 
na proporção de até $20 \%$, executando a função protetora da membrana celular e evitando alterações na bicamada fosfolipídica.

Conclusão: Este trabalho colabora com a ampliação de dados atuais sobre a criopreservação de gametas, sobretudo nos grandes carnívoros. A partir desse estudo, será possível que pesquisas futuras sejam realizadas a fim de investigar novos protocolos de criopreservação e adequá-los a espécies ameaçadas.

Palavras-chave: Reprodução, Carnívoros, Criopreservação.

\section{Referências:}

AMSTISLAVSKY, S.; LINDEBERG, H.; LUVONI, G.C. Reproductive technologies relevant to the genome resource bank incarnivora. Reprod Domest Anim, v. 47, n. 1, p. 164-175, 2012.

ARAUJO, G.R. Comparison of semen samples collected from wild and captive jaguars (Panthera onca) by urethral catheterization after pharmacological induction. Anim Reprod Sci, v.195, p. 1-7, 2017.

MAKSUDOV, G.Y.; SHISHOVA, N.V. Katkov II. In the cycle of life: cryopreservation of post-mortem sperm as a valuable source in restoration of rare and endangered species In Columbus AM, Kuznetsov LV., eds, Endangered Species: New Research Edition, Ed 1 NOVA Publishers, New York, p. 189-240. 2008.

SILVA, A.R.; MORATO R.G.; SILVA, L.D.M. The potential for gamete recovery from non-domestic canids and felids. Anim Reprod Sci, v. 81, p. 159-175, 2004.

SILVA, H. et al. Comizzoli P. Semen Cryopreservation and Banking for the Conservation of Neotropical Carnivores. Biopreserv Biobank. 2018.

TEODORO, L.O. et al. Seasonal aspects of reproductive physiology in captive male Maned Wolves (Chrysocyon brachyurus, Illiger, 1815). Reprod Domest Anim, v. 47, p. 250-255, 2012. 


\section{CIRURGIA DE FECALOMA EM FELINO: RELATO DE CASO}

Pietra Roanny Costa Mota SOUSA; Pedro Ferreira De Sousa JUNIOR; Lauanne Rodrigues BARROS; Gabriel Satoru OHASHI; Raffael Oliveira EUFRASIO; Thales Rodrigues

COSTA; Luís Eduardo Leite Leão MARTINS.

E-mail de contato: pietra.roanny@gmail.com

Introdução: A definição de fecaloma consiste em fezes ressecadas e contidas no colón. Em gatos a patologia é mais comum podendo estar ligada desde fatores genéticos aos etossomaticos. O objetivo desse trabalho é relatar a ocorrência clínica/cirúrgica de um caso de fecaloma diagnosticado em um paciente felino.

Metodologia: Foi atendida em uma clínica veterinária no município de Floriano-PI, um felino S.R.D. (sem raça definida), fêmea de 4 anos e 3,3 $\mathrm{kg}$ com queixa de não defecar a 15 dias. Durante a anamnese, o tutor afirmou que fornecia apenas ração à vontade durante o dia. No exame físico, foi notada distensão abdominal, sensibilidade à palpação e uma massa densa e sugestiva no interior das alças intestinais e constipação. Devido à gravidade da situação, optou-se por realizar a laparotomia exploratória. No hemograma solicitado, observou-se discreta anemia microcítica hipocrômica. Em seguida, a paciente foi encaminhada para o procedimento cirúrgico. A MPA foi realizada com diazepam $(0,5 \mathrm{mg} / \mathrm{kg})$ IV e cetamina $(5 \mathrm{mg} / \mathrm{kg}) \mathrm{IV}$, realizou-se a tricotomia, antissepsia prévia e definitiva. A anestesia foi feita com isoflurano diluído em oxigênio 100\% em sistema semiaberto em um aparelho de anestesia inalatória. Com o animal em plano anestésico, realizou uma incisão na altura da linha alba, isolando lateralmente e de forma manual as alças intestinais, acessando diretamente a região colônica do intestino grosso.

Resultado: Após a exposição do colón, realizou-se uma incisão em sentido longitudinal ao colón cuidadosamente para não ocorrer contaminação da cavidade. Devido ao tempo nobre de cirurgia, foi realizado a sutura das camadas serosa e mucosa com padrão de sutura simples e cushing com fio de nylon 3-0, em seguida a linha alba em padrão simples isolado com fio nylon 2-0 e posterior dermorrafia com nylon 2-0. Foi removido aproximadamente $200 \mathrm{~g}$ de conteúdo fecal ressecado. No pós-operatório, foi realizada alimentação com proteínas hidrossolúveis pastosas de alta digestibilidade. As medicações em pós-operatório continham metronidazol na dose de $(20 \mathrm{mg} / \mathrm{kg}) \mathrm{IV}$, enrofloxacina na dose de $(5 \mathrm{mg} / \mathrm{kg}) \mathrm{SC}$ e tramadol na dose de $(1 \mathrm{mg} / \mathrm{kg}) \mathrm{IM}$ por 2 dias.

Conclusão: $O$ paciente recebeu alta depois de 3 dias de internação, retornando com 10 dias para retirada dos pontos, foi recomendado ao tutor a administração de alimentação pastosa, água sempre fresca e limpa para evitar possíveis recidivas. Apesar de ser uma patologia rotineira nas clínicas de pequenos animais, as causas de fecaloma em felinos podem variar bastante. $O$ tratamento clínico com o uso de laxantes só gera efeitos satisfatório nos primeiros dias de obstrução, sendo assim recomendado o procedimento cirúrgico. Portanto, a enterectomia e os cuidados pós-operatórios foram eficientes, proporcionando uma boa recuperação da paciente.

Palavras-chave: constipação; felino; cirurgia. 


\section{Referências:}

ABONIZIO, A.G. et al. Fecaloma em gato: relato de caso. Colloquium Agrariae, v. 14, n. 2, p. 177-182, abr./jun. 2018.

FOSSUM, T.W. Cirurgia de pequenos animais. 3. ed. Rio de Janeiro, 2008. p. 1632.

SILVA, A.C. Constipação e obstipação em gatos: abordagem clínica e cirúrgica. Clínica Veterinária, v. 3, p. 17-22, 1998.

SILVA, G. et al. Radiodiagnóstico de fecaloma em gatos domésticos (Felis catus) relato de caso. In: XIII JORNADA DE ENSINO, PESQUISA E EXTENSÃO, 2013, Recife. Anais. Recife: Universidade Federal Rural de Pernambuco, 2013. 


\title{
MANEJO TERAPÊUTICO PARA ASPERGILOSE EM PINGUIM-DE- MAGALHÃES (SPHENISCUS MAGELLANICUS)
}

\author{
Joyce Cristina SILVA; Adriana Rodriguez dos SANTOS.
}

\section{E-mail de contato: joycecristina1998s@gmail.com}

Introdução: A aspergilose é considerada a maior causa de mortalidade de pinguins em cativeiro. Os Centros de Recuperação de Animais Marinhos recebem anualmente de dezenas a centenas de pinguins-de-Magalhães (Spheniscus magellanicus) para reabilitação. Muitos destes, acabam vindo a óbito por aspergilose, a qual influencia significativamente nas taxas de liberação e reintrodução dos pinguins recebidos, em seu habitat natural (FILHO R.P.S.; RODRIGUEZ V. et al).

Os pinguins-de-magalhães (Spheniscus magellanicus) são aves marinhas, pertencentes à Ordem Sphenisciformes. Segundo a lista vermelha da International Union for Conservation of Nature (IUCN), esta espécie está quase ameaçada de extinção, e em 2018, quando foi realizado o último levantamento, a população estimada de pinguins-de-magalhães foi de 1.100 .000 a 1.600 .000 pares. Durante a migração, esses animais ficam expostos às adversidades do meio, principalmente à poluição dos oceanos com derivados de óleo, e chegam aos centros de reabilitação debilitados, tornando-os suscetíveis ao desenvolvimento da aspergilose (XAVIER, M. O. et al.).

A aspergilose é uma infecção fúngica oportunista, que acomete primariamente o trato respiratório através da inalação dos conídios do fungo do gênero Aspergillus, que podem ser dispersados pelo ar, ou pela água (RODRIGUEZ V. et al). O Aspergillus, é um fungo filamentoso com hifas hialinas, septadas e ramificadas. Dentro desse gênero, a espécie responsável pelo maior número de casos clínicos tanto em pinguins quanto nos demais hospedeiros é a $A$. fumigatus (XAVIER, M. O. et al). O fungo se desenvolve principalmente no trato respiratório, porém pode acometer outros órgãos por via hematógena. Os sinais clínicos geralmente são inespecíficos, como letargia, fraqueza, dispneia, dificultando o diagnóstico (CABANA, A.L. et al.).

Metodologia: Trata-se de uma revisão de literatura sistemática, que teve como objetivo identificar um padrão no manejo terapêutico preconizado para o tratamento da aspergilose em pinguins-de-magalhães. Para isso, foi realizado um levantamento bibliográfico em setembro de 2020, utilizando as bases de dados SciELO, Pubmed e Google Acadêmico. As palavras-chave utilizadas na busca foram: "Aspergilose em pinguins", "Aspergillus" "Aspergillus Sphenisciformes". A partir das buscas realizadas, foram encontrados 7 artigos publicados entre 2006 e 2018 que foram usados para realizar a presente revisão.

Resultados: Para um protocolo de tratamento adequado, será necessário avaliar se o animal possui aspergilose localizada ou disseminada. No primeiro caso, é indicado terapia antifúngica sistêmica, com remoção cirúrgica do aspergiloma. Já na disseminada, é preconizado tratamento com anfotericina $B$ que pode ser administrada por nebulização, via intratraqueal ou endovenosa. Antifúngicos orais como Cetoconazol, Itraconazol, Terbefina e Voriconazol também podem ser utilizados (HIPPÓLITO, A.G et al., FILHO R.P.S). Em um dos estudos foi constatado, em alguns animais, a resistência adquirida ao Itraconazol e ao Voriconazol pelo A. fumigatus, o que pode trazer complicações para o tratamento (L.A. BEERNAERT, et al).

Conclusão: Ao detectar aspergilose em pinguins o tratamento pode ser cirúrgico, através da 
remoção do aspergiloma, quando possível, ou por tratamento clínico com antifúngicos sistêmicos. Porém, de modo geral, o prognóstico para aspergilose em pinguins é ruim por se tratar de uma infecção agressiva e com difícil diagnóstico devido aos sinais clínicos inespecíficos.

Palavras-chave: Aspergilose, Spheniciformes, Cativeiro.

Referências:

HIPPÓLITO, A.G. et al. A alteração hematológica e bioquímica em pinguins-demagalhães (Spheniscus magellanicus) tratados com Itraconazol por um mês. MVeZ, p. 43, 2012.

CABANA, A.L. et al. Alterações anátomo-patológicas da Aspergilose em pinguins. XVI CIC, 29 nov. 2017. XVI Congresso de iniciação científica, Faculdade de Agronomia Eliseu Maciel, 2017.

XAVIER, M.O. et al. Aspergilose em pinguins-de-magalhães (Spheniscus magellanicus): relato de caso. Veterinária e Zootecnia, v. 13, n. 1, p. 28-32, 17 abr. 2006.

FILHO, R.P.S. Avaliação epidemiológica de aspergilose em pinguins-de-magalhães (Spheniscus magellanicus) no centro de recuperação de animais marinhos - FURG; Pelotas; [s. N.]; 2012

BEERNAERTK, L.A. et al Avian aspergillus fumigatus strains resistant to booth itraconazole and voriconale. Antimicrobial Agents and Chemotherapy Apr, v. 53, n. 5, p. 2199-2201, 2009.

RODRIGUEZ V. et al. Isolamento e identificação de fungos do gênero Aspergillu spp. De água utilizada na reabilitação de pinguins-de-magalhães. Ciênc. anim. bras., Goiânia, v. 16, n. 4, p. 567-573, Dez. 2015. Available from $<$ http://www.scielo.br/scielo.php?script=sci_arttext\&pid=S180968912015000400567\&lng=en\&nrm=iso $>$. access on $27 \quad$ Sept. 2020. https://doi.org/10.1590/1089-6891v16i428509.

THE IUCN RED LIST OF THREATENED SPECIES. BirdLife International.2018. Spheniscus magellanicus. 2018; Disponível em https://dx.doi.org/10.2305/IUCN.UK.20182.RLTS.T22697822A132605485.en. Downloaded on 26 September 2020 


\title{
MONITORAMENTO DO Vibrio cholerae NA VIGILÂNCIA AMBIENTAL DE RECIFE-PERNAMBUCO
}

\author{
Gabriel da Silva FERREIRA; Viviane de Lima NUNES; Maria Luiza Ribeiro Bastos da \\ SILVA; Jurandir Alves de ALMEIDA JÚNIOR; Mariana Gomes Ferreira Machado de \\ SIQUEIRA.
}

\section{E-mail de contato: gabrielsilvaferreira@live.com}

Introdução: O Vibrio cholerae (sorogrupos O1 e O139) é uma bactéria produtora de uma enterotoxina que pode desencadear uma série de distúrbios à saúde. Entre eles, vômito, náuseas e diarreia constituem os principais sintomas, provocando rápida desidratação e assim gerando danos gradativos à circulação sanguínea, comprometendo a função renal, água e minerais do corpo, afligindo todos os sistemas do indivíduo. Desde os anos 90 a região nordeste, assim como todo o Brasil tornou-se vítima dessa doença, sendo notificados mais de 168.598 casos até 2001. A principal via de contaminação é a fecal/oral, estando correlacionada ao saneamento básico e à higiene. Diante disso, considerando a possibilidade de ressurgimento da bactéria no país, medidas preventivas para impossibilitá-la tornam-se imprescindíveis para o bem-estar humano, animal e ambiental. Sabe-se que os microrganismos, especialmente os de interesse médico, caso não sejam detectados a tempo, tem potencial para se espalhar celeremente, além disso, dependendo de seu tempo de incubação e virulência, conseguem ser disseminadas de forma silenciosa, gerando os surtos, epidemias e nos casos extremos, as pandemias. O objetivo desse trabalho foi realizar uma análise do banco de dados da vigilância ambiental para rastreamento do $V$. cholerae no Recife. Metodologia: O levantamento das informações foi realizado por meio da base de dados do Programa Nacional de Vigilância da Qualidade da Água para Consumo Humano (VIGIAGUA), na Gerência de Vigilância Ambiental e Controle de Zoonoses (GEVACZ) do Recife, que monitorou condições físico-químicas favoráveis para o desenvolvimento da bactéria em canais, rios, lagoas e áreas estuarinas nos Distritos Sanitários (DS), em consonância com histórico de ocorrência de cólera na região. Assim determinou com precisão pontos estratégicos para o monitoramento do $V$. cholerae. Então, foram compilados os laudos laboratoriais durante os últimos 4 anos - de 2016 a 2019 - que analisaram os materiais biológicos coletados com a técnica de Moore, fazendo uso de mechas nos pontos distribuídos em todos os oito DS do município.

Resultados: O quantitativo de mechas analisadas nos anos 2016, 2017, 2018 e 2019 foram respectivamente, $169(24,42 \%), 92(13,29 \%), 201(29,04 \%)$ e $230(33,23 \%)$, com um total de 692 amostras coletadas, onde todas $(100 \%)$ foram negativas em relação ao $V$. cholerae. No entanto, duas amostras nos meses de janeiro e junho de 2019, nos DS III e V, constaram positivo para o Vibrio parabaemolyticus. Apesar da redução de coletas ocorrida no ano de 2017 comparado a 2016, a vigilância ambiental do município ampliou significativamente o número de amostras nos anos subsequentes, alguns DS que não foram realizadas coletas em 2016 e 2017, passaram a ser monitorados a partir de 2018 , posto isso, atualmente $100 \%$ dos DS estão sendo acompanhados.

Conclusão: As análises realizadas para a precoce identificação das Vibrio spp. demonstraram ser de grande importância, tendo em vista que a identificação da bactéria $V$. parabaemolyticus também é de relevância e responsável por gastroenterites, possibilitando assim medidas 
corretivas em tempo hábil. Por essa razão, o acompanhamento preventivo se torna vital para a preservação da saúde e uma forma de consolidar o conceito de saúde única.

Palavras-chave: Cólera, Saneamento básico, saúde única.

\section{Referências:}

BRASIL, Ministério da Saúde. Cólera: causas, sintomas, transmissão, tratamento e diagnóstico. V-3.7.008. Brasil. Disponível em: http://www.saude.gov.br/saude-de-az/colera. Acesso em: 10 set. 2020.

BRASIL, Ministério da Saúde. Orientações técnicas para o monitoramento ambiental do Vibrio cholerae. 1. ed. Brasília: Editora MS, 2016. ISBN 978-85-334-2462-3. Disponível em: $\quad$ http://bvsms.saude.gov.br/bvs/publicacoes/monitoramento_ ambiental_vibrio_cholerae.pdf. Acesso em: 10 set. 2020.

GUIMARÃES, M.J. et al. $4^{a}$ Expoepi: Mostra nacional de experiências bem-sucedidas em epidemiologia, prevenção e controle de doenças. Mapeamento de riscos e agravos à saúde relacionados com água no Recife: uma estratégia para reestruturação das ações da vigilância da qualidade da água de consumo humano, do monitoramento ambiental do Vibrio cholerae e das doenças diarreicas agudas. Brasília, 4. ed., p. 18-20, 23 nov. 2004. ISBN 85-334-1016-6.

SILVEIRA, D.R. et al. Fatores de patogenicidade de Vibrio spp. de importância em doenças transmitidas por alimentos. Arquivos do Instituto Biológico, v. 83, p. 1-7, 2016. Acesso em: 8 set. 2020. 


\title{
OS IMPACTOS DA URBANIZAÇÃO E CRENDICES POPULARES SOBRE OS OURIÇOS-CACHEIROS DA ESPÉCIE Coendou spinosus (F. CUVIER, 1823)
}

\author{
Karen Pierin SILVESTRE; Fernanda Cunha Boer MACÁRIO; Bárbara Antonieta Ribeiro \\ PILÃO.
}

E-mail de contato: pierinkaren@gmail.com

Introdução: A espécie Coendou spinosus é popularmente conhecida como Ouriço-Cacheiro é comumente encontrada em nossa região, tendo registros de ocorrência do sul da Bahia até o Uruguai e Paraguai. Esta espécie sofre grandes impactos nos centros urbanos devido à desinformação e crendices populares, como acreditar que o animal lance seus espinhos venenosos nas pessoas e animais domésticos. Acrescenta-se a isto o aumento da urbanização, diminuindo as áreas naturais e favorecendo o contato dos humanos e cães domésticos com a espécie. Como os Ouriços-Cacheiros podem ser considerados animais oportunistas, o centro urbano favorece sua ocorrência, pois há oferta de alimentos, como pomar das residências, lixeiras abertas, ração de animais domésticos exposta, além de favorecer a utilização de forros de residências para repouso e reprodução. Toda essa proximidade tem gerado grande conflito, pois trata-se de uma espécie com movimentação lenta e comportamento tranquilo, sendo facilmente atacada por pessoas e cães, além de sofrer muito com atropelamentos, cercas elétricas e concertinas. O presente estudo objetivou demonstrar e avaliar o impacto da urbanização e das crendices populares sobre os Ouriços-Cacheiros que são recebidos no Centro de Reabilitação de Animais Silvestres - CRAS NÚCLEO DA FLORESTA, localizado no município de São Roque/SP.

Metodologia: Foram analisados os dados sobre todos os Ouriços-Cacheiros recebidos pelo CRAS, no município de São Roque/SP, no período compreendido entre Agosto de 2019 e Setembro de 2020, totalizando 21 animais, sendo avaliados os motivos de recebimento do animal, condições físicas e seu destino, como óbito, reabilitação para soltura ou soltura imediata.

Resultados: Dos animais analisados, 05 foram recebidos sem injúrias físicas, encontrados em residências ou empresas, possibilitando sua Soltura Imediata, representando 24\% do total; 12 animais foram recebidos com ferimentos gerados por cães ou ataque de pessoas, necessitando do processo de Reabilitação para posterior Soltura, representando 57\% do total; e 04 animais foram recebidos com ferimentos muito graves ocasionados por atropelamentos ou concertina, vindo à Óbito, representando os $19 \%$ finais do total.

Discussão: Os resultados do presente estudo demonstram que as ações antrópicas diretas. através de ataque de pessoas e atropelamentos, ou indiretas, através de cercas elétricas, concertinas ou cães domésticos, representam 76\% dos motivos que levam os OuriçosCacheiros ao CRAS, e representam praticamente $20 \%$ dos óbitos da espécie nos centros urbanos. A Educação Ambiental é fundamental para que a espécie seja protegida através da divulgação de informações corretas sobre o animal, sobre os cuidados com os cães domésticos e também sobre a educação no trânsito.

Palavras-chave: Ouriço-Cacheiro, Fauna Sinantrópica, Educação Ambiental. 


\section{Referências:}

BRANCO, A.M. Resgate e reabilitação da fauna silvestre oriunda do comércio ilegal na América do Sul. 1a. Conferência Sul Americana Sobre o Comércio Ilegal de Fauna Silvestre, Brasília, Brasil, 2000.

KEINAN, G. The effects of stress and desire for control on superstitious behavior. Personality and social psychology bulletin, v. 28, 2002.

PRADO, T.R., FERREIRA, A.A.; GUIMARÃES, Z.F.S. Efeito da implantação de rodovias no cerrado brasileiro sobre a fauna de vertebrados. Acta Sci. Biol. Sci., v. 28, n. 3, p. 237-241, 2006.

ROACH, N.; NAYLOR, L. 2016. Coendou spinosus. The IUCN Red List of Threatened

e.T20630A22213974. https://dx.doi.org/10.2305/IUCN.UK.2016-

Species ,2016:

2.RLTS.T20630A22213974.en. Downloaded on 30 September 2020. 


\section{PRINCIPAIS ENDOPARASITOS QUE ACOMETEM O PEIXE-BOI- MARINHO (Trichechus manatus manatus LINNAEUS, 1758) - REVISÃO SISTEMÁTICA}

Aksa Ingrid Vieira BATISTA; Gabriel Vinícius Carvalho DE LUCENA; Marina Neves de Assis AGUIAR; Felipe José da Costa ANDRADE; Gilmara Miguel SOUZA; Raphaela Bueno Mendes BITTENCOURT; Andrea Moura DE CAMARGO; Jhonatan Henrique Lima da ROCHA.

E-mail de contato: aksaingridmv@gmail.com

Introdução: O peixe-boi-marinho (Trichechus manatus manatus LINNAEUS, 1758) pertence à ordem Sirenia e família Trichechidae, sendo um dos mamíferos aquáticos mais ameaçados do Brasil, e atualmente classificado como vulnerável à extinção. Essa espécie é encontrada em águas marinhas costeiras quentes e rios, tendo hábitos alimentares herbívoros. Dentre as principais afecções que acometem animais silvestres, as endoparasitoses se destacam, já que muitas vezes podem ser zoonóticas, representando um risco para a saúde humana. Além disso, os parasitos podem influenciar a reprodução e a sobrevivência do hospedeiro, e em suas taxas de mortalidade e natalidade, o que é um obstáculo para a conservação. A maioria dos estudos de parasitologia em sirênios foi realizada na subespécie nativa da Flórida, T. $m$. latirostris, portanto, há informações limitadas disponíveis para a subespécie tropical T. $m$. manatus. Assim sendo, o objetivo do presente trabalho é revisar as principais espécies parasitas encontradas em T. manatus manatus.

Metodologia: No mês de outubro do ano de 2020, cerca de 30 artigos foram baixados na plataforma Google Acadêmico e PubMed em inglês e português sobre parasitologia em animais silvestres e parasitos em peixe-boi-marinho, usando as palavras "Parasitos em Trichechus manatus manatus", nos idiomas já citados acima. Desses, apenas 12 artigos e um livro foram selecionados, levando em consideração a subespécie escolhida (Trichechus manatus manatus) e a caracterização do parasito em no mínimo gênero. No total, relatou-se 12 espécies de parasitos já relatados em T. manatus manatus, sendo apenas 4 para o Brasil.

Resultados: Os protozoários coccídeos (Protozoa: Coccidia) encontrados em peixes-boismarinhos (Trichechus manatus manatus LINNAEUS, 1758) foram principalmente Cryptosporidium spp. para o norte e nordeste do Brasil; Eimeria manatus e E. nodulosa para Porto Rico e Colômbia. Também foram achados anticorpos para o parasito Toxoplasma gondii pelo teste de aglutinação em látex (LAT) no Brasil. Além disso, foram encontrados também Entamoeba sp. (Protozoa: Amoebozoa) na Cordilheira dos Andes, Colômbia; e o flagelado Giardia sp. (Protozoa: Diplomonadida) em amostras fecais de peixe-bois-marinhos no mesmo país e no norte e nordeste do Brasil. Quanto aos trematódeos digenéticos (Trematoda: Digenea), foi encontrado o parasito Pulmonicola cochleotrema, para os estados de Sergipe, Paraíba e Ceará no Brasil, para Porto Rico e República Dominicana. Além disso, ovos de Moniligerum blairi foram recuperados em amostras da referida espécie em Porto Rico; Chiorchis groschafti em Porto Rico e México; Nudacotyle undicola em Porto Rico e Colômbia; e C. fabaceus para Colômbia, República Dominicana e México. Na classe Nematoda, apenas o Rhabditida Heterocheilus tunicatus foi relatado, para Porto Rico, República Dominicana e México.

Conclusão: Esse trabalho contribui para a compilação referente aos dados ecológicos, bem como para a conservação de T. m. manatus. A partir desse estudo, será possível que pesquisas 
futuras sejam realizadas com a finalidade de compreender a dinâmica desses parasitos em peixes-bois-marinhos e assim investigar as consequências que estes venham a causar e interferir no bem-estar da espécie hospedeira.

Palavras-chave: Mammalia, Parasitologia, Sirênios.

\section{Referências:}

BORGES, J.C.G. et al. Ocorrência de Cryptosporidium spp. em peixes-boi marinhos (Trichechus manatus) e funcionários envolvidos no manejo da espécie. Estudos de Biologia, v. 29, n. 66, 2007.

BORGES, J.C.G. et al. Ocorrência de infecção Cryptosporidium spp. em peixe-boi marinho (Trichechus manatus). Revista Brasileira de Parasitologia Veterinária, v. 18, n. 1, p. 60-61, 2009.

BORGES, J.C.G. et al. Pulmonicola cochleotrema (Digenea: Opisthotrematidae) in Antillean manatees (Trichechus manatus manatus) from the north-eastern region of Brazil. 2016.

BORGES, J.C.G. et al. Cryptosporidium spp. and Giardia sp. in aquatic mammals in northern and northeastern Brazil. Diseases of aquatic organisms, v. 126, n. 1, p. 25-31, 2017.

CARVALHO, V.L. et al. Occurrence of Pulmonicola cocbleotrema (syn. Cocbleotrema cocbleotrema) (Digenea: Opisthotrematidae) in Antillean manatees (Trichechus manatus manatus) in Brazil. Latin American Journal of Aquatic Mammals, v. 7, n. 1-2, p. 47-52, 2009.

CUBAS, Z.S.; SILVA, J.C.R.; CATÃO-DIAS, J.L.; Tratado de Animais Selvagens. 2. ed. São Paulo: ROCA, 2014.

DE OLIVEIRA, S.G. et al. Prevalência de Bertiella sp. em um grupo de bugios-pretos, Alouatta caraya (Humbolt, 1812). A Primatologia no Brasil, 2011.

MIGNUCCI-GIANNONI, A.A. et al. Helminths from a stranded manatee in the Dominican Republic. Veterinary Parasitology, v. 81, n. 1, p. 69-71, 1999.

PIRES, J.M.L. et al. Parasitological research in urine from marine manatees (Trichechus manatus manatus) maintained in captivity in Brazil. Scientific Electronic Archives, v. 9, n. 4, p. 47 52, 2016.

SILVA, J.C.R. et al. Pesquisa de anticorpos anti-Toxoplasma gondii, Leptospira interrogans e Brucella abortus em peixes-bois-marinhos (Trichechus manatus manatus) mantidos em cativeiro. 
In: V Congresso e X Encontro da Associação Brasileira de veterinários de Animais Selvagens, 2001, São Paulo-SP. Resumos..., 2001. p. 27.

VÉLEZ, J. et al. Occurrence of endoparasites in wild Antillean manatees (Trichecbus manatus manatus) in Colombia. International Journal for Parasitology: Parasites and Wildlife, v. 7, n. 1, p. 54-57, 2018.

VÉLEZ, J. et al. Parasite fauna of wild Antillean manatees (Trichechus manatus manatus) of the Andean Region, Colombia. Parasites \& vectors, v. 12, n. 1, p. 1-9, 2019.

WYROSDICK, H. et al. Internal parasites of the two subspecies of the West Indian manatee Trichechus manatus. Diseases of Aquatic Organisms, v. 130, n. 2, p. 145-152, 2018. 


\title{
PREVALÊNCIA DE LESÕES OCULARES EM PINÍPEDES (MAMMALIA: PINNIPIDAE) MANTIDOS EM CATIVEIRO - REVISÃO SISTEMÁTICA
}

\author{
Aksa Ingrid Vieira BATISTA; Gabriel Vinícius Carvalho DE LUCENA; Raphaela Bueno \\ Mendes BITTENCOURT; Gilmara Miguel SOUZA; Jhonatan Henrique Lima DA \\ ROCHA; Andrea Moura DE CAMARGO; Marina Neves de Assis AGUIAR; Felipe José \\ da Costa ANDRADE.
}

E-mail de contato: aksaingridmv@gmail.com

Introdução: Os pinípedes (Mammalia: Pinnipidae) são mamíferos carnívoros e aquáticos, que podem ser encontrados desde os polos até os trópicos. Na natureza, os pinípedes possuem o comportamento de mergulhar nos oceanos para capturar suas presas, e como o fundo do mar reflete pouca luz solar, além de dificilmente precisarem olhar para cima, estes animais naturalmente não são expostos a uma grande quantidade de raios ultravioleta (UV). No entanto, pinípedes mantidos sob cuidados humanos são frequentemente alojados em piscinas de cor azul clara, que refletem a maior parte desses raios. Além disso, os animais geralmente precisam olhar para cima com frequência devido a alimentação por tratadores, treinadores ou pelo público. Essas condições podem causar danos aos olhos de pinípedes de cativeiro, e outros fatores como a má nutrição, a falta de sombra, o uso exacerbado de oxidantes na água e o aumento da salinidade podem colaborar com essa predisposição. Embora muitos avanços tenham sido feitos nas práticas de manejo, nutrição, e na medicina de mamíferos marinhos, uma grande porcentagem dos pinípedes ainda sofre de doenças oculares. Dessa maneira, o objetivo desse trabalho é revisar a prevalência dessas lesões em focídeos, otarídeos e morsas.

Metodologia: No mês de outubro do ano de 2020, cerca de 16 artigos foram baixados na plataforma Google Acadêmico e PubMed em inglês e português sobre pinípedes e lesões oculares nesses animais, utilizando as palavras "doenças oculares em pinípedes", nos idiomas já citados acima. Desses, apenas 7 artigos, 2 teses e um livro foram selecionados, levando em consideração apenas revisões de literatura, relatos de casos, e estudos que demonstrassem a prevalência das doenças oftálmicas desses indivíduos, compreendendo os anos entre 2000 e 2020.

Resultados: Em um estudo realizado por COLITZ et al. (2010) utilizando-se 111 pinípedes, doenças oculares foram diagnosticadas, a partir de exame oftálmico, em 49,5\% dos animais. MILLER e colaboradores (2013), usando-se a histopatologia dos globos oculares de 70 pinípedes, demonstraram que 43 possuíam doença de córnea, 23 possuíam catarata, e os outros animais apresentavam phthisis bulbi, neoplasia, deposição amiloide, doença fúngica, ou deformidades decorrentes de trauma. Outro trabalho realizado também por COLITZ e colaboradores (2010) descreveu que 64,6\% de otarídeos apresentavam estágios de queratite progressiva. Além disso, uma pesquisa realizada por GRANDE et al. (2017) em 15 pinípedes demonstrou que a ceratite ulcerativa foi uma patologia relativamente frequente $(7 / 15)$, onde 6 de 7 pacientes $(85,7 \%)$ apresentaram lesões simultaneamente em ambos os olhos. Por fim, COLITZ et al (2019) demonstrou que em 319 pinípedes, ceratopatias foram identificadas em $56,7 \%$ dos animais, sendo 51,4\% com ambos os olhos afetados, 3,4\% com apenas o olho esquerdo afetado e 1,9\% com o olho direito afetado.

Conclusão: Conclui-se que lesões oculares são afecções frequentes na clínica de pinípedes, com relativa prevalência de doenças de córnea. Dessa forma, sabendo que esses animais 
possuem essa predisposição, maiores cuidados relacionados ao manejo, como a melhoria na nutrição, na qualidade da água e nos designs de recintos, podem ser realizados com a finalidade de aumentar a longevidade, assim como o bem-estar desses indivíduos, colaborando para fins de conservação.

Palavras-chave: Oftalmologia, Otariidae, Focidae.

\section{Referências:}

COLITZ, C.M.H. et al. Risk factors associated with cataracts and lens luxations in captive pinnipeds in the United States and the Bahamas. Journal of the American Veterinary Medical Association, v. 237, n. 4, p. 429-436, 2010.

COLITZ, C.M.H. et al. Characterization of progressive keratitis in Otariids. Veterinary Ophthalmology, v. 13, p. 47-53, 2010.

COLITZ, C.M.H. et al. Bilateral ocular anomalies in a S outh A frican fur seal (A rctocephalus pusillus pusillus). Veterinary ophthalmology, v. 17, n. 4, p. 294-299, 2014.

COLITZ, C.M.H. et al. Factors associated with keratopathy in captive pinnipeds. Journal of the American Veterinary Medical Association, v. 255, n. 2, p. 224-230, 2019.

CUBAS, Z.S.; SILVA, J.C.R.; CATÃO-DIAS, J.L.; Tratado de Animais Selvagens. 2. ed. São Paulo: ROCA, 2014.

GAGE, L.J. Captive pinniped eye problems, we can do better. Journal of Marine Animal Ecology, v. 4, n. 2, p. 25-29, 2011.

GRANDE, F. et al. Incidence and management of ulcerative keratitis in a pinnipeds population under human care. Veterinary Medicine and Animal Sciences, v. 5, n. 1, p. 1, 2017.

MILLER, S. et al. A retrospective survey of the ocular histopathology of the pinniped eye with emphasis on corneal disease. Veterinary ophthalmology, v. 16, n. 2, p. 119-129, 2013.

SANCHES, I.T. et al. Lensectomia em Zalophus californianus, como tratamento de catarata bilateral. 2019. Tese de Doutorado. Universidade de Lisboa, Faculdade de Medicina Veterinária.

SOUSA, C.S.O. Abordagem cirúrgica e análise histopatológica de cataratas em focas: dois casos clínicos e sete amostras analisadas. 2019. Dissertação de Mestrado. Universidade de Évora. 


\title{
GASTROTOMIA EM CÃO DA RAÇA HUSKY SIBERIANO PARA RETIRADA DE MEIA - RELATO DE CASO
}

\author{
Anne Valéria Costa ALVES ${ }^{1}$; Gabriela Campos de Souza COSTA; Lohana Ramos \\ MOURÃO; Mayane Ferreira GOMES; Rafael Saavedra GOMES.
}

E-mail de contato: annevcosta@gmail.com

Introdução: Cães jovens são curiosos e passam boa parte do seu tempo mastigando objetos. Entretanto, esse ato pode causar malefícios ao organismo do animal se for ingerido, sendo a obstrução a causa mais frequente da ida à clínica nesses casos. Segundo Fossum (2014), corpo estranho (CE) é qualquer objeto ingerido pelo animal e que não pode ser digerido, como pedras, plásticos, metais ou que são digeridas muito lentamente (ossos) e que podem causar obstrução em graus variáveis. O objetivo desse trabalho é relatar o caso de um cão que engoliu uma meia de $55 \mathrm{~cm}$, a qual alojou-se entre o estômago e intestino delgado.

Metodologia: Foi atendido na clínica veterinária Vetcenter 24h, localizada em Macapá-AP, um cão da raça Husky siberiano, macho, de 6 meses de idade, pesando 13,8 kg, com suspeita de corpo estranho. Ao avaliar a ultrassonografia, diagnosticou-se a presença de corpo estranho linear obstruindo a região gástrica e duodenal. Desse modo, foi indicado a gastrotomia para retirada do CE, uma meia de aproximadamente $55 \mathrm{~cm}$ de comprimento. Foi administrada a medicação pré-anestésica utilizando acepromazina $(0,03 \mathrm{mg} / \mathrm{kg})$ e tramadol $(3 \mathrm{mg} / \mathrm{kg})$ via IV. Para indução anestésica foi utilizado propofol $(5 \mathrm{mg} / \mathrm{kg})$ e quetamina $(2 \mathrm{mg} / \mathrm{kg})$. Após intubação endotraqueal manteve-se a anestesia com isoflurano e oxigênio $100 \%$ ambos inalatórios, e administrou-se no período trans-operatório o fentanil $2,5 \mathrm{mg} / \mathrm{kg}$ via IV. Foi feita uma incisão na linha média ventral abdominal desde o processo xifoide até a região retroumbilical. Inspecionou-se de todos os componentes abdominais para incisar o estômago. Em geral, a técnica foi de acordo com Fossum (2014), isolou-se o estômago dos outros componentes abdominais com compressas cirúrgicas umedecidas para reduzir a contaminação. Colocou-se pontos de fixação para auxiliar na manipulação do estômago e ajudar a evitar o derramamento do conteúdo gástrico. Fez-se uma incisão gástrica em uma área hipovascular do aspecto ventral do estômago, entre as curvaturas maior e menor. Para o fechamento do estômago optou-se por sutura Schmieden e sutura de Cushing ambos com fio absorvível número 3.0 poliglactina 910. Para o fechamento da incisão abdominal usou-se nylon número 0 , fez-se redução do subcutâneo com fio cromado 2.0 e sutura da pele com nylon 2.0.

Resultados: Para a obtenção correta do diagnóstico se faz necessário o histórico, exame físico e exames de imagem. O animal do caso estudado apresentava sinais característicos de deglutição de corpo estranho, típico de um material que não conseguia prosseguir no trato gastrointestinal, obstruindo parcialmente o piloro e duodeno, não permitindo a passagem da 
ração, ocasionando os vômitos intermitentes. O prognóstico do animal foi bom, não havendo ferimentos no trato digestório.

Conclusão: A sintomatologia clínica e tratamento desta afecção variam conforme o material, tamanho e forma do corpo estranho ingerido, além da sua localização no trato gastrointestinal do animal (PARRA et al., 2012). O cão transcendeu normalmente durante a cirurgia, mantendo quadro estável e se recuperou bem.

Palavras-chave: corpo estranho, estômago, cirurgia.

\section{Referências:}

FOSSUM, T.W. Cirurgia de pequenos animais. 4. ed. Rio de Janeiro: Elsevier, 2014. Cap. 20, p. $1295-1300,1339-1341$.

PARRA, T. C.; BERNO, M. D. B.; GUIMARÃES A. C. M.; ANDRADE, L. C. A.; MOSQUINI, A. F.; e MONTANHA, F. P. Ingestão de corpo estranho em cães. Revista científica eletrônica de medicina veterinária. Ano IX. Número 18. São Paulo, 2012. 


\title{
LINFOMA DIFUSO DE CÉLULAS GRANDES - RELATO DE CASO
}

\author{
Matheus Ferreira LOURENÇO; Adaíli Cauê Alves ARARUNA; Camila Mirelle da Silva \\ NUNES; Luciana Alves ARARUNA.
}

\section{E-mail de contato:mf405829@gmail.com}

Introdução: $O$ linfoma ou linfossarcoma é o tumor linfoide que se origina em órgãos linfo hematopoiético sólidos, como linfonodo, baço, fígado e agregados linfóides associados à mucosa (FIGUERA et al., 2006). Acredita-se na possível etiopatogenia multifatorial envolvendo eventos genéticos, deficiência imunológica, exposição à radiação ionizante e carcinógenos químicos (CUNHA et al,2011). Sinais inespecíficos como hiporexia, perda de peso e vômito, podem ocorrer e relacionam-se com o subestágio "b" da Organização Mundial da Saúde (OMS) (ROSENTHAL, 1990). As anormalidades hematológicas encontradas são igualmente variadas (MORRISON, 2005). Os estadiamentos mais frequentes em cães são os quadros mais avançados, III, IV e V, em virtude da provável inabilidade dos proprietários em identificar as manifestações da doença em fase inicial, o que reflete diretamente no prognóstico, pois alguns estudos demonstram que cães com estágio IV e $\mathrm{V}$ apresentam uma sobrevida mais curta (TESKE, 1994).

Metodologia: As informações apresentadas nesse trabalho, foram obtidas por meio de acompanhamento do animal, e revisão da literatura referente ao caso abordado. $\mathrm{O}$ animal foi atendido no consultório Amigo de Pelo no município de João Pessoa (PB) pela veterinária Luciana Alves Araruna no dia 15 de maio de 2019, um cão, fêmea da raça Pit Bull com 5 anos de idade, castrada e pesando $30 \mathrm{~kg}$. O tutor trouxe o animal e sua principal queixa foi o aparecimento de vários nódulos espalhados pelo corpo, esses nódulos foram aparecendo em um curso de um mês, crescendo em tamanho e quantidade. Foi realizado o exame clínico do animal e também exames laboratoriais, hemograma completo, perfil bioquímico, foi coletado material do linfonodo poplíteo e de 2 tumores para a análise tecidual.

Resultados: Com a realização dos exames observou-se alterações, no hemograma as taxas do Eritrograma, Leucograma e Plaquetas estavam abaixo além do adequado, resultando em uma anemia, leucopenia absoluta e trombocitopenia, Os resultados das bioquímicas séricas com relação a ureia e creatinina deu dentro dos valores de referência, com exceção das enzimas AST e ALT, resultado da deposição de imunocomplexos, Nos exames citológico e de análise tecidual $O$ resultado foi conclusivo para Linfoma difuso de grandes células, não epiteliotrópico considerado como neoplasia. (SCHNEIDER et al., 2013).

Conclusão: Este trabalho serviu para a compreensão a respeito do linfoma de células grandes. Sendo observado que o linfoma é uma neoplasia maligna que acomete muitos cães, e que na maioria das vezes a sobrevida é curta, por isso a importância de um diagnóstico rápido e preciso em conjunto com um tratamento adequado para o aumento da sobrevida do animal. No caso apresentado, o animal veio a óbito devido ter um quadro clínico crítico.

Palavras-chave: Linfossarcoma, cão, neoplasia. 


\section{Referências:}

CUNHA, F.M. et al. Linfoma multicêntrico em Canis familiaris (cão doméstico): estudo retrospectivo de 60 casos, entre agosto de 2009 e dezembro de 2010, no município de São Paulo-SP. Journal of the Health Sciences Institute, v.29, n.4, p.209-301, 2011.

FIGUEIRA, R. A. et al. Aspectos clinico-patológicos de 43 casos de linfoma em cães. MEDVEP-Revista Científica de Medicina Veterinátia- Pequenos Animais e Animais de Estimação. v.4, n.12, p.139-146, 2006.

MORRISON, W.B. Lymphoma in dogs and cats. Jackson: Teton NewMedia, 2005. 124p. ROSENTHAL, R.C. The treatment of multicentric canine lymphoma. Veterinary Clinics of North America Small Animal Practice, v.20, n.4, p.1093-1104, 1990.

SCHNEIDER, S.M.; CIANCIOLO, R.E.; NABITY, M.D.; CLUBB, F.J.; BRONW 1. C.A; LEES, G.E. Pevalence of immune- complex glomerulonephritides in dogs biopsied fo suspected glomerular disease: 501 cases (2007-2012). Journal of Veterinary Internal, Medicine, v. 27, p. 67-75, 2003.

TESKE, E. Canine malignant lymphoma: a review and comparison with human nonHodgkin lymphoma Veterinary Quarterly, The Hague, v.16, p209-219,1994. 


\section{ICTIOFITIRÍASE - REVISÃO DE LITERATURA}

Saul Mota BEZERRA; Isadora Martins dos Santos AMORIM; Isadora Bessa Miranda ANDRADE; Mariana Almeida BRITO; SILVA, Micaely Barbosa de Oliveira SILVA; Seldon Almeida de SOUZA.

E-mail de contato: saulbezerra10@gmail.com

Introdução: $\mathrm{O}$ agente etiológico da ictiofitiríase em peixes é o Ichthyophthirius multifiliis (Fouquet, 1876). A enfermidade é também conhecida como "doença dos pontos brancos", devido aos sinais clínicos característicos. Trata-se de um protozoário ciliado, cujo ciclo de vida se completa nas células epiteliais dos hospedeiros. O objetivo desse trabalho foi realizar uma revisão de literatura sobre a ictiofitiríase por se tratar de uma doença amplamente distribuída nos peixes, sendo causa das maiores perdas mundiais nas pisciculturas de água doce (HARPER, 2003) e pouco relata na literatura no Brasil.

Metodologia: A ictiofitiríase é provocado pelo protozoário Ichthyophthirius multifilizs (PRIETO, 1991) e ocorre quando os animais são submetidos a quedas bruscas de temperaturas, ele penetra a pele do peixe para concluir o seu ciclo de vida. A penetração ocorre geralmente entre as escamas, nadadeiras, cavidade oral e tecido branquial. O ciclo de vida desse parasita é simples, quando instalado no hospedeiro se alimenta de secreções, fragmentos teciduais e células inflamatórias, depois de maduro ele sai da pele e forma uma cápsula, onde começa a se dividir, e, ao final, ele rompe essa cápsula e volta ao hospedeiro e assim o ciclo recomeça. O principal sintoma são as manchas brancas no animal e em situações mais graves, os peixes apresentam-se apáticos, com anorexia, mudança de coloração de pele, aumento da produção de muco e dificuldade respiratória (PRIETO, 1991). A transmissão ocorre através de outro animal infectado; a água e objetos funcionam como meio de transmissão. O diagnóstico é simples, rápido e feito a partir da raspagem tanto da pele quanto das brânquias, para análise. O tratamento é prolongado e requer muitos cuidados, pois nem todo animal suporta o tratamento sendo necessário fazer interrupções além de piorar a qualidade da água (NOGA et al., 2013). Podemos citar como tratamento os banhos prolongados com sal, formalina e malaquita, este último sendo tóxico para algumas espécies e a mudança da temperatura da água para $>30$ pois ocorre a interrupção no desenvolvimento do parasita (NOGA et al., 2013).

Resultados: No Brasil, a piscicultura é uma atividade de grande importância e é preciso estar atento ao manejo dos animais, para que não sofram com doenças como a ictiofitiríase, provocando prejuízos financeiros ou na saúde dos consumidores. Apesar de ser uma doença conhecida por quem cria peixes, ele possui um ciclo de vida simples, porém é necessário cuidados específicos, para o tratamento desses animais pois é uma enfermidade bastante letal fazendo com que o animal fique apático e tenha dificuldade respiratória. Tornando-se um perigo pois o peixe doente pode acabar infectando outros animais. Além de que, foi descoberto uma cepa do protozoário que não precisa sair do peixe para completar o ciclo, dificultando o tratamento.

Conclusão: É necessário um estudo maior acerca dessa enfermidade aqui no Brasil por se tratar de uma doença comum em peixes, podendo constituir um prejuízo financeiro para o mercado e na saúde do animal e consumidores. Além de um estudo mais para um protocolo eficaz no tratamento.

Palavras-chave: Protozoário, Psicultura, Parasita. 


\section{Referências:}

HARPER, C. Introducing Ichthyophthirius multifiliis: A Devastating Parasite. Aquaculture Magazine, v. 29, p. 40-52, 2003.

NOGA, E. J. Fish Disease: Diagnosis and Treatment. 2. ed. John Wiley \& Sons, 2011.

PRIETO, A.; FAJER, E.; VINJOY, M. Manual para la Prevención y el Tratamiento de Enfermedades en Peces de Cultivo en Agua Dulce. Santiago: FAO, 1991, p. 65. 


\section{ESPLENECTOMIA TOTAL EM CÃO COM NEOPLASIA MESENQUIMAL MALIGNA EM BAÇO - RELATO DE CASO}

Julia de Oliveira SILVA; Pietra Roanny Costa Mota SOUSA; Vanessa Saraiva SOUSA; Selmar MOREIRA; Jacqueline Maria Canuto de SOUSA; Emanuelle Karine Frota BATISTA.

E-mail de contato: julia.oliveer16@gmail.com

Introdução: Nas últimas décadas, o número de casos de animais diagnosticados com neoplasias teve aumento considerável. Isto advém do fato destes estarem com uma maior sobrevida, e devido a isso, surgiram novas opções terapêuticas e formas de manejo para garantir a melhoria da qualidade de vida destes pacientes. Como o baço é um órgão que possui diversas funções, dentre elas a imunológica, a estocagem e maturação de células sanguíneas, este acaba por ser o alvo de diversas patologias. Os tumores de células mesenquimais têm a origem nas células mesenquimais de tecidos conjuntivo, sanguíneo, linfático, nervoso, adiposo, muscular e ósseo, possuindo macroscopicamente formas e tamanhos diferenciados. A ultrassonografia mostra-se eficaz na identificação de tumores esplênicos e devido ao risco de hemorragias, a esplenectomia é a medida terapêutica mais utilizada, podendo-se realizar a citologia aspirativa após o procedimento para a identificação de malignidade ou não.O objetivo desse trabalho é relatar um caso de esplenectomia total devido a uma neoplasia mesenquimal maligna em baço de um cão atendido em uma clínica veterinária na cidade de Teresina-Piauí.

Metodologia: Um cão da raça Pinscher, fêmea, de 10 anos de idade foi atendido com relato de falta de apetite, apatia e aumento do abdômen e ao exame físico apresentava sensibilidade dolorosa na região, temperatura retal de $38^{\circ} \mathrm{C}$ e desidratação. Indicou-se um exame de ultrassonografia da região abdominal no qual foi possível observar o Baço com volume moderadamente aumentado sugestivo de esplenomegalia com superfície irregular, parênquima com ecogenicidade preservada e topografia habitual com presença de estrutura nodular, subcapsular, com ecogenicidade mista. Nos exames hematológicos, evidenciou-se anemia microcítica normocrômica e uma eosinopenia. Foi solicitado o internamento do paciente para tratamento de suporte e realização de esplenectomia total e posterior citologia aspirativa por agulha fina (CAAF).

Resultados: $O$ nódulo encontrado no baço tinha aproximadamente $5 \mathrm{~cm}$ de cor brancacenta, formato arredondado e consistência firme. $\mathrm{Na}$ CAAF verificou-se grande quantidade de células sanguíneas e várias células mesenquimais alongadas, variando de células fusiformes com citoplasma disposto oposto ao núcleo a celular ovais e estreladas, evidenciando atipias como anisocitose, pleomorfismo, cromatina grosseira, macrocariose, célula evidentes e multinucléolos, sugestivo de neoplasia mesenquimal maligna. Após a esplenectomia, a paciente ficou sendo monitorada para verificar sua recuperação e adaptação, recebendo alta após melhora clínica.

Conclusão: A esplenectomia total tem-se mostrado um tratamento eficiente em casos de neoplasias malignas. Os exames complementares como a ultrassonografia e citologias mostram-se de extrema importância para diagnósticos de neoplasias esplênicas e, associados ao tratamento cirúrgico, tendem a resultar em um melhor prognóstico para o paciente.

Palavras-chave: Baço, Nódulo, Maligna. 


\section{Referências:}

BARBOZA, D.V. et. al. Estudo retrospectivo de neoplasmas em animais de companhia atendidos no hospital de clínicas veterinárias da universidade federal de Pelotas durante 2013 a 2017. Pubvet, 2019, v.13, n.4, a312, p. 1-12.

COUTO, C.G.; NELSON, R.W. Linfadenopatia e esplenomegalia. In: NELSON, R.W; COUTO, C.G Medicina Interna de pequenos animais, 5. ed. Rio de Janeiro: Elsevier, p. 3667 $-3684,2015$.

DALECK, C.R.; FONSECA, C.S.; CANOLA, J.C. Oncologia em cães e gatos. Rio de Janeiro, 2016. Roca.

FOSSUM, T.W.; CAPLAN, E.R. Cirurgia do Sistema Hemolinfático. In. FOSSUM, T.W. Cirurgia de pequenos animais 4. ed. Rio de Janeiro: Elsevier, 2014. p. 685 - 700.

SILVA, A.S. Estudo retrospectivo das neoplasias mesenquimais caninas diagnosticadas no Setor de Patologia Animal da EVZ/UFG. 2020, xii, 46f.: il. 


\title{
SOBRE OS ORGANIZADORES
}

\author{
FELIPE JOSÉ DA COSTA ANDRADE \\ http://lattes.cnpq.br/6279033074483233
}

Coordenador discente do Projeto Kaiabí: Educação em Medicina da Conservação e Saúde Única. Bolsista PIBEX/UFPI do Projeto de Educação Ambiental com comunidades rurais no sul do Piauí. Voluntário do Programa de Estudo Manejo Conservação do Bicho-preguiça (PEMCBP). Acadêmico de Medicina Veterinária da Universidade Federal do Piauí (2017), Diretor Administrativo de Animais Silvestres da Empresa União Veterinária Júnior - Univet Jr. (2020), fez parte da Diretoria Executiva do Grupo de Estudos de Animais Selvagens do Brasil - GEAS BRASIL (2019-2020), Ex-Presidente e membro efetivo do Grupo de Estudos em Biodiversidade - GBIO (2019), Presidente do Centro Acadêmico de Medicina Veterinária - UFPI/ CPCE (2019), Diretor de Parcerias do Grupo de Estudos de Animais Selvagens GEAS UFPI/TERESINA (2019), Diretor de Projetos e Difusão do Grupo de Estudos em Reabilitação Animal - REABVET (2019), Membro Efetivo do Grupo de Gestão Ambiental - GGA (2020). Possui linhas de pesquisa em Conservação, Clínica e Manejo de Animais Silvestres, Agroecologia, Educação Ambiental, Medicina Integrativa, Medicina da Conservação e Saúde Única, Literatura Educacional e Leptospirose em Animais Domésticos e Silvestres.

\section{MARDÔNIO LUAN VIEIRA DA SILVA http://lattes.cnpq.br/0396729552935427}

Possui ensino médio segundo grau pela escola Professor Gabriel Almeida Café (2012). Acadêmico de Medicina Veterinária da Universidade Federal do Piauí, campus Bom Jesus.

\section{ANNE VALÉRIA COSTA ALVES \\ http://lattes.cnpq.br/0256506521587480}

Acadêmica de Medicina Veterinária na Universidade Federal do Piauí. Atuante na área de pequenos animais e silvestres. Fundadora e presidente do Grupo de Estudos em Reabilitação animal - ReabVET (2019), membro efetiva do Grupo de Estudos em Biodiversidade - GBio (2019), criadora de conteúdo da revista InfoPet (2020). Possui linhas de pesquisa em: clínica e medicina integrativa de pequenos animais e silvestres, educação ambiental.

\section{VITÓRIA DA SILVA PEREIRA \\ http://lattes.cnpq.br/5138364856928633}

Acadêmica de Medicina Veterinária na Universidade Federal do Piaui. Vice-Presidente da Empresa União Veterinária Júnior - Univet Jr. (2020). 


\section{LEONARDO DA VINCI BOGÉA CONCEIÇÃO \\ http://lattes.cnpq.br/8887448993010809}

Acadêmico de Medicina Veterinária (Bacharelado) pela Universidade Federal do Piauí UFPI, Campus Professora Cinobelina Elvas - CPCE (2017). Técnico em Agropecuária pelo Instituto Federal de Educação, Ciência e Tecnologia do Maranhão - IFMA (2011-2013). Diretor Financeiro da Empresa União Veterinária Júnior - Univet Jr. (2020). Editor de Mídia do Jornal Acadêmico Ô Sabiá - UFPI/CPCE (2019). Foi monitor da disciplina Parasitologia Veterinária (2019.2).

\section{MARÍLIA GABRYELLE GUIMARÃES DE MACÊDO} http://lattes.cnpq.br/5736811828842092

Bolsista PIBIC-UFPI do Projeto Vigilância da Febre do Nilo e outras encefalites virais em cavalos no Piauí. Iniciação Científica Voluntária (ICV) no Projeto Mulas e Burros: seriam eles também hospedeiros acidentais para Febre do Nilo no Piauí?.Voluntária do Programa de Estudo Manejo Conservação do Bicho-preguiça (PEMCBP). Representante Discente de Medicina Veterinária da UFPI-CPCE. Acadêmica de Medicina Veterinária na Universidade Federal do Piauí (2017). Presidenta (2021) e Ex Secretária Geral (2020-2021) do Grupo de Estudos em Biodiversidade - GBIO. Ex-Secretária de Comunicação da Liga Acadêmica de Medicina Veterinária Preventiva - LAVEP (2019). Foi monitora da disciplina Anatomia Descritiva Animal II (2018.2 e 2019.1) e monitora da disciplina Histologia e Embriologia Animal (2019.2). Atuante no Setor de Animais Silvestres do Hospital Veterinário Universitário da Universidade Federal do Piauí. Possui como linhas de pesquisa Clínica, Cirurgia e Manejo de Animais Silvestres e Domésticos, Leptospirose e Febre do Nilo Ocidental em Animais domésticos e silvestres.

\section{ISABELLA LUSTOSA DOS SANTOS \\ http://lattes.cnpq.br/8556850611133488}

Acadêmica de Medicina Veterinária da Universidade Federal do Piaú (2018), faz parte da Diretoria Executiva da empresa Junior do curso de medicina veterinária UnivetJR. Foi monitora da disciplina de fisiologia animal (2019).

\section{JOÃO HENRIQUE DE MORAES DOS SANTOS \\ http://lattes.cnpq.br/8309957747266081}

Acadêmico de Medicina Veterinária na Universidade Federal do Piaú, campus Bom Jesus (2018-). Vice-presidente do Grupo de Estudos em Reabilitação Animal (2019). Secretário de Meio Ambiente do Centro Acadêmico de Medicina Veterinária (2019). Criador de conteúdo da Revista Científica InfoEquestre (2020). Atuante na área de Grandes Animais com ênfase em Equinos. Possui como linha de pesquisa: Fisioterapia e Reabilitação Animal, Medicina Veterinária Integrativa. 


\section{GISELLE BARBOSA RODRIGUES}

http://lattes.cnpq.br/5839767111883432

Acadêmica de Medicina Veterinária na Universidade Federal do Piauí (2018). Atuante na área de pequenos animais. Diretora de Marketing do Grupo de Estudos em Felinos (2019-2020), Diretora da Coordenação de Combate a Opressão do Diretório Central Estudantil - DCE (2019-2020).

\section{ROMÃO ALVES DO NASCIMENTO NETO \\ http://lattes.cnpq.br/5123808998143151}

Acadêmico de medicina veterinária, da universidade federal do Piauí (2016).

Iniciação Científica Voluntária (ICV) Análise ultrassonográfica de carcaça de coelhos da raça Nova Zelândia. Tesoureiro do centro acadêmico de medicina veterinária na universidade federal do Piauí (2019). Tesoureiro do Núcleo de Estudo e Pesquisa e extensão em EquinosNEEQUI (2019). Foi monitora da disciplina de bioquímica veterinária (2017.1), genética (2018.1), parasitologia veterinária (2019.1), Anatomia Descritiva Animal II (2019.2), patologia clínica (2020.1), atualmente da disciplina de clínica de equídeos (2020.2) e monitor adjunto da coordenação (2020.3). Possui como linhas de pesquisa na área de clínica-cirúrgica de animais domésticos e área de vigilância sanitária. 


\section{ÍNDICE REMISSIVO}

A

M

Anfíbios, 8, 9

Aquarismo, 40

Aspergilose, 47, 48

C

Canídeo, 42

Canídeos, 13

Cativeiro, 29, 48

cirurgia, 10, 45, 59

clínica, 3, 10, 11, 20, 35, 37, 39, 45, 46, 56, 58, 59, 64

Clínica, 35, 40, 46

Colapso traqueal, 11

Comportamento, 25, 29, 31, 42

Conservação, 8, 9, 17, 22, 23, 25, 31

Correção cirúrgica, 11, 18

Criopreservação, 44

Mamíferos, 25

Mammalia, 27, 54, 56

\section{$\mathbf{N}$}

neoplasia, 56, 60, 64

Nódulo, 64

Oftalmologia, 57

Parasitologia, 27, 34, 54
Protozoário, 62
Psicultura, 62

Q

Diagnóstico, 13

quelônios, 15

$\mathbf{R}$

Radiografia, 38

Reprodução, 44

F

S

felino, 45

Fungos, 15

saúde única, 3, 33, 50

V

Vitamina, 38 

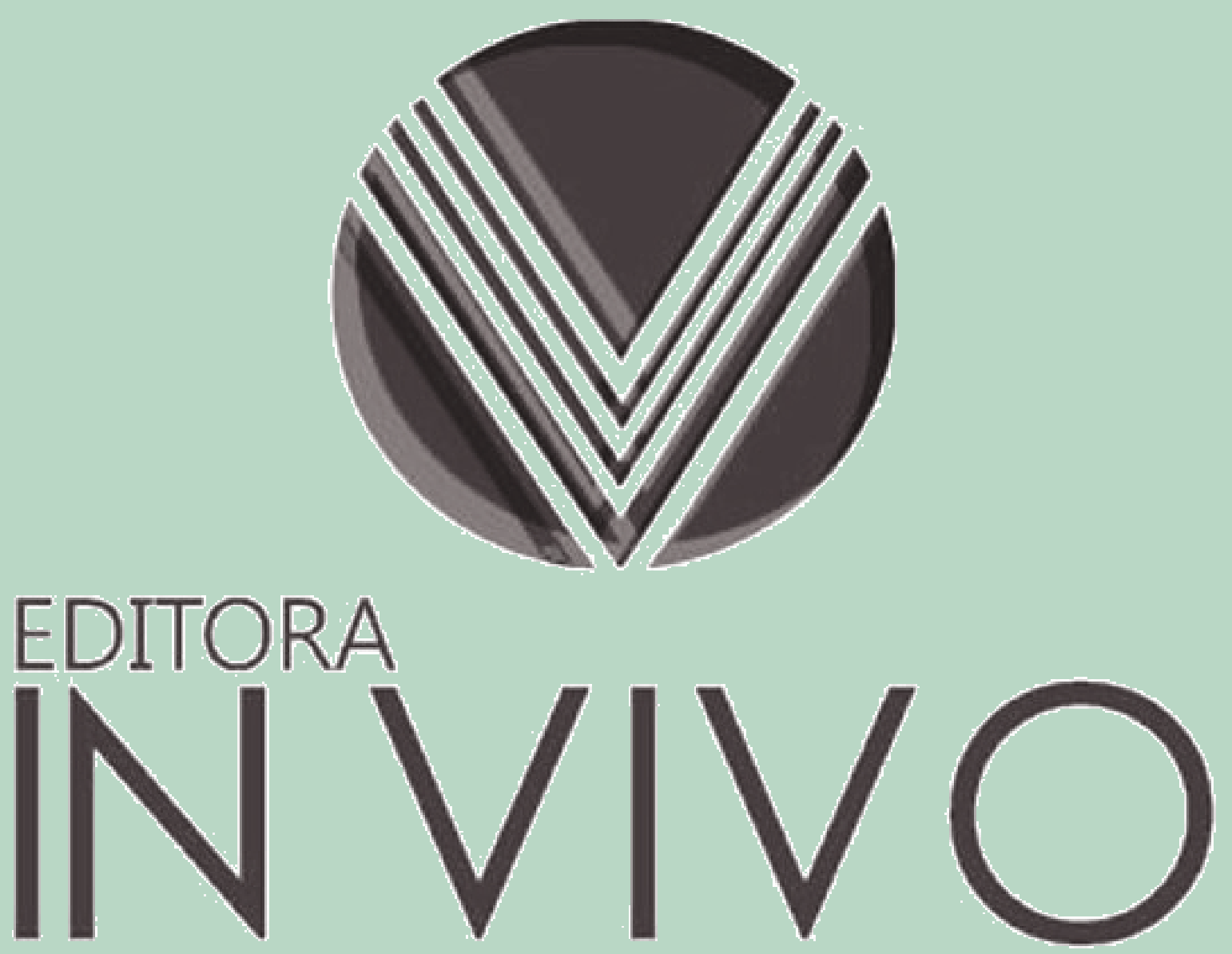

ACESSE:

www.editorainvivo.com

Avance na ciência! Venha ser In Vivo! 